\title{
High-Mannose Specific Lectin and Its Recombinants from a Carrageenophyta Kappaphycus alvarezii Represent a Potent Anti-HIV Activity Through High-Affinity Binding to the Viral Envelope Glycoprotein gp120
}

\author{
Makoto Hirayama $^{1} \cdot$ Hiromi Shibata $^{1} \cdot$ Koji Imamura $^{2}$ - Takemasa Sakaguchi ${ }^{3}$. \\ Kanji Hori $^{1}$
}

Received: 2 July 2015 / Accepted: 10 November 2015 / Published online: 12 December 2015

(C) Springer Science+Business Media New York 2015

\begin{abstract}
We previously reported that a high-mannose binding lectin KAA-2 from the red alga Kappaphycus alvarezii, which is an economically important species and widely cultivated as a source of carrageenans, had a potent anti-influenza virus activity. In this study, the full-length sequences of two KAA isoforms, KAA-1 and KAA-2, were elucidated by a combination of peptide mapping and cDNA cloning. They consisted of four internal tandem-repeated domains, which are conserved in high-mannose specific lectins from lower organisms, including a cyanobacterium Oscillatoria agardhii and a red alga Eucheuma serra. Using an Escherichia coli expression system, an active recombinant form of KAA-1 (His-tagged rKAA-1) was successfully generated in the yield of $115 \mathrm{mg}$ per a litter of culture. In a detailed oligosaccharide binding analysis by a centrifugal ultrafiltration-HPLC method with 27 pyridylaminated oligosaccharides, His-tagged rKAA1 and rKAA-1 specifically bound to high-mannose $N$-glycans with an exposed $\alpha 1-3$ mannose in the D2 arm as the native lectin did. Predicted from oligosaccharide-binding specificity, a surface plasmon resonance analysis revealed that the recombinants exhibit strong interaction with gp120, a heavily glycosylated envelope glycoprotein of HIV with high
\end{abstract}

Kanji Hori

kanhori@hiroshima-u.ac.jp

1 Graduate School of Biosphere Science, Hiroshima University, 1-4-4 Kagamiyama, Higashi-Hiroshima 739-8528, Japan

2 Medical and Biological Laboratories Co., Ltd., 1063-103 Terasawaoka, Ina, Nagano 396-0002, Japan

3 Department of Virology, Institute of Biomedical and Health Sciences, Hiroshima University, 1-2-3 Kasumi, Minami-ku,

Hiroshima 734-8551, Japan association constants $\left(1.48-1.61 \times 10^{9} \mathrm{M}^{-1}\right)$. Native KAAs and the recombinants inhibited the HIV-1 entry at $\mathrm{IC}_{50} \mathrm{~s}$ of low nanomolar levels $(7.3-12.9 \mathrm{nM})$. Thus, the recombinant proteins would be useful as antiviral reagents targeting the viral surface glycoproteins with high-mannose $N$-glycans, and the cultivated alga $K$. alvarezii could also be a good source of not only carrageenans but also this functional lectin(s).

Keywords Anti-viral lectin · HIV · Alga · Carageenophyta . Kappaphycus alvarezii

\section{Introduction}

Human immunodeficiency virus (HIV) infects CD4+ cells, where a viral envelope glycoprotein gp120 interacts with a receptor CD4 and a co-receptor CXCR4 or CCR5 of the host cells, and subsequent insertion of a viral envelope glycoprotein gp41 into the host cell membrane triggers the fusion followed by entry of the virus (Kilby and Eron 2003). gp120 is a highly glycosylated protein, as half of its total mass is accounted by about $24 \mathrm{~N}$-linked glycans including complex and high-mannose types (Geyer et al. 1988). These densely attached $\mathrm{N}$-glycans shield the viral surface proteins to escape from neutralizing antibody recognition (Wei et al. 2003; Bonomelli et al. 2011). On the other hand, carbohydratebinding agents that target those glycans on the viral envelope exhibit potent anti-viral activities via interfering the interaction between gp120 and CD4 (Hansen et al. 1989; Balzarini et al. 1991; Charan et al. 2000; Dey et al. 2000; Swanson et al. 2010).

Several high-mannose $N$-glycan-binding lectins are newly found and marked as potential microbicides having anti-HIV activities, such as cyanobacterial lectins of cyanovirin-N (CV- 
N) from Nostoc ellipsosoprum (Boyd et al. 1997), scytovirin (SVN) from Scytonema varium (Bokesch et al. 2003) and MVL from Mycrosystis viridis (Bewley et al. 2004), a bacterial lectin of actinohivin $(\mathrm{AH})$ from actinomycete Longispora albida (Chiba et al. 2001), and algal lectins of griffithsin (GRFT) from a red alga Griffithsia sp. (Mori et al. 2005) and BCA from a green alga Boodlea coacta (Sato et al. 2011b). These lectins show strong anti-HIV activities through their binding to mannoside structures on gp120. However, high-mannose recognition mode subtly differed among them, as well as the primary structures were clearly distinct (Sato et al. 2011b; Koharudin and Gronenborn 2014). High-mannose $N$ glycan structures are also present on the surfaces of the other enveloped viruses such as influenza virus, hepatitis $C$ virus (HCV), human herpes virus (HHV), West Nile virus, severe acute respiratory syndrome-related coronavirus (SARS-CoV), and Ebola virus (Okuno et al. 1992; Vigerust and Shepherd 2007). This suggests that high-mannose-binding lectins could also inactivate the entries of those viruses into host cells (Barrientos et al. 2003; Helle et al. 2006; O'Keefe et al. 2003, 2010).

A lectin ESA-2 from a red alga Eucheuma serra (Kawakubo et al. 1997) was recently found to possess the unique binding specificity with the preferential affinity for high-mannose $\mathrm{N}$-glycans bearing the nonreducing terminal 11-3 Man in D2 arm (Hori et al. 2007). Since then, several lectins with similar binding specificity were isolated from some lower organisms, including red algae (Kawakubo et al. 1999; Sato et al. 2011a; Hung et al. 2011, 2015), a cyanobacterium (Sato et al. 2000, 2007), and bacteria (Cumsky and Zusman 1979; Sato et al. 2012; Koharudin et al. 2012; Whitley et al. 2013). Interestingly, these lectins commonly had tandem-repeated structures of a similar domain composed of about 67 amino acids, and grouped into two types of four and two repeats (Hori et al. 2007; Sato et al. 2007; Sato and Hori 2009) as exemplified with ESA-2 (four repeats) and a lectin OAA (two repeats) from a freshwater cyanobacterium Oscillatoria agardhii. Thus, we demonstrated the occurrence of a new lectin family which is widely distributed in lower organisms, indicating that ESA-2 and OAA are orthologous to each other. Among them, OAA has been characterized in details. The structural analyses of OAA and its complexes with oligomannosides revealed that this lectin recognized a core unit, Man $\alpha 1-6(\operatorname{Man} \alpha 1-3) \operatorname{Man} \alpha 1-6(\operatorname{Man} \alpha 1-3) \operatorname{Man} \beta$ - of the branched mannoside in high-mannose $N$-glycan (Koharudin et al. 2011; Koharudin and Gronenborn 2011, 2014). This recognition mode of OAA was novel as the other highmannose-binding lectins mostly recognized the nonreducing end mannoses. Potent anti-HIV activities of this lectin family, including ESA-2, OAA, Pseudomonas fluorescens agglutinin (PFA), Myxococcus xanthus agglutinin (myxobacterial hemagglutinin, MBHA) (Koharudin et al. 2012), and Burkholderia oklahomensis agglutinin (BOA) (Whitley et al. 2013) were represented as expected by their specific binding nature to high-mannose sugar moiety. Strong anti-influenza virus activities through binding to the envelope hemagglutinin protein were also shown in PFL (identical to PFA) (Sato et al. 2012) and KAA-2 isolated from a cultivated red alga Kappaphycus alvarezii (Sato et al. 2011a).

Algae belonging to genus Eucheuma and Kappaphycus are widely cultivated as food and carageenophyte. K. alvarezii cultivation was originally started in the Philippines in latter half of the 1960s using the local varieties selected from the wild (Doty 1973; Parker 1974; Bindu and Levine 2011). After four decades, the Kappaphycus became the most widely cultivated commercial eucheumoid (Bindu and Levine 2011) and has globally been introduced for cultivation and some experimental purposes in tropical and subtropical area, including Asia, Africa, the Pacific Island, and American countries (Ask et al. 2003; Bindu and Levine 2011). We recently reported that KAA-2 isolated from the cultivated sample of $K$. alvarezii preferentially recognized high-mannose-type oligosaccharides bearing an exposed $\alpha 1-3$ Man at the nonreducing end in D2 arm and inhibited infection of various influenza virus strains with $\mathrm{EC}_{50} \mathrm{~s}$ of low nanomolar levels through direct binding to the viral envelope hemagglutinin protein, which has several high-mannose $N$-glycans (Sato et al. 2011a). The results also suggest that KAA-2 may belong to a new lectin family mentioned above. However, the primary structure of KAA is unknown yet as well as its anti-HIV activity. In this study, we elucidated the primary structure of KAA-2 using peptide mapping and complementary DNA (cDNA) cloning and prepared its active recombinants using an Escherichia coli expression system. The native and

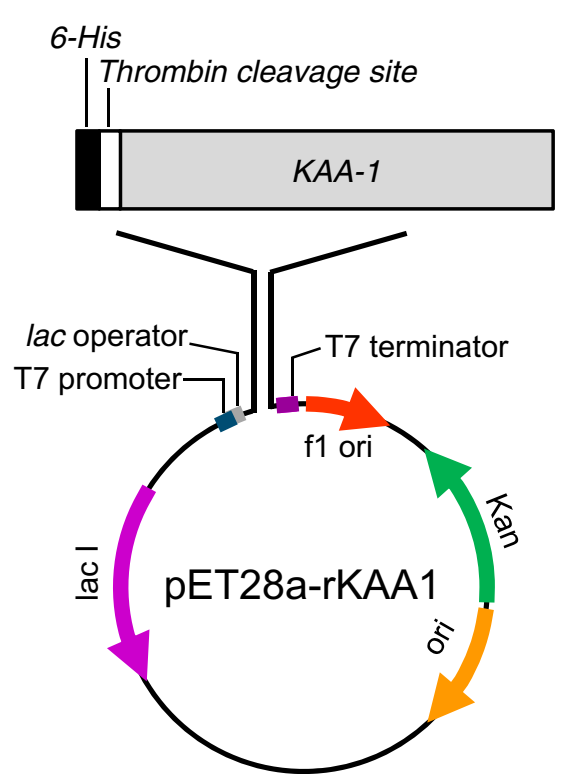

Fig. 1 A diagram of recombinant KAA-1 (rKAA-1) expression vector pET28a-rKAA1. rKAA-1 was expressed as a 6-His- and thrombin cleavage site-fused protein 
recombinant lectins were examined for sugar-binding specificity and anti-HIV activity, including binding nature to gp120.

\section{Materials and Methods}

\section{Materials}

K. alvarezii lectins KAA-1 and KAA-2 (previously declared as ECA-1 and ECA-2) and Eucheuma serra lectin ESA-2 were prepared as described previously (Kawakubo et al.
1997, 1999) and kept at $-20{ }^{\circ} \mathrm{C}$ until use. The cultivated specimen of $K$. alvarezii was stored in RNAlater (Life Technologies, CA, USA) at $-20{ }^{\circ} \mathrm{C}$ until RNA extraction. A vector pGEM-T Easy (Promega, WI, USA) and E. coli strain DH- $5 \alpha$ were used for subcloning PCR-amplified products. An expression vector pET-28a(+) (Merck, Darmstadt, Germany) and an E. coli strain SHuffle T7 Express (New England Biolabs, MA, USA) were used for recombinant lectin preparation. Pyridylaminated (PA)-sugars were purchased from Takara Bio (Tokyo, Japan), except PA-derivatives of oligomannosides including mannotriose (Man $\alpha 1-6(\operatorname{Man} \alpha 1-$ 3) Man-OH) and mannopentaose (Man $\alpha 1-6(\operatorname{Man} \alpha 1-$
Fig. 2 Isolation of PE-KAA-2 and PE-ESA-2 by reverse-phase HPLC. PE-KAA-2 (a) and PEESA-2 (b) were purified by RPHPLC on YMC-Pack PROTEINRP column. The eluate was monitored by absorbance at $280 \mathrm{~nm}$ and the active fraction represented by a bar was recovered. Deconvoluted mass spectra of purified PE-KAA-2 (a) and PE-ESA-2 (b) using ESI-MS (LCQ) are also represented. $\mathbf{c}$ SDS-PAGE of PE-KAA-2 (lane 1) and PE-ESA-2 (lane 2). Five micrograms of protein was loaded in each lane. $M$ molecular weight marker
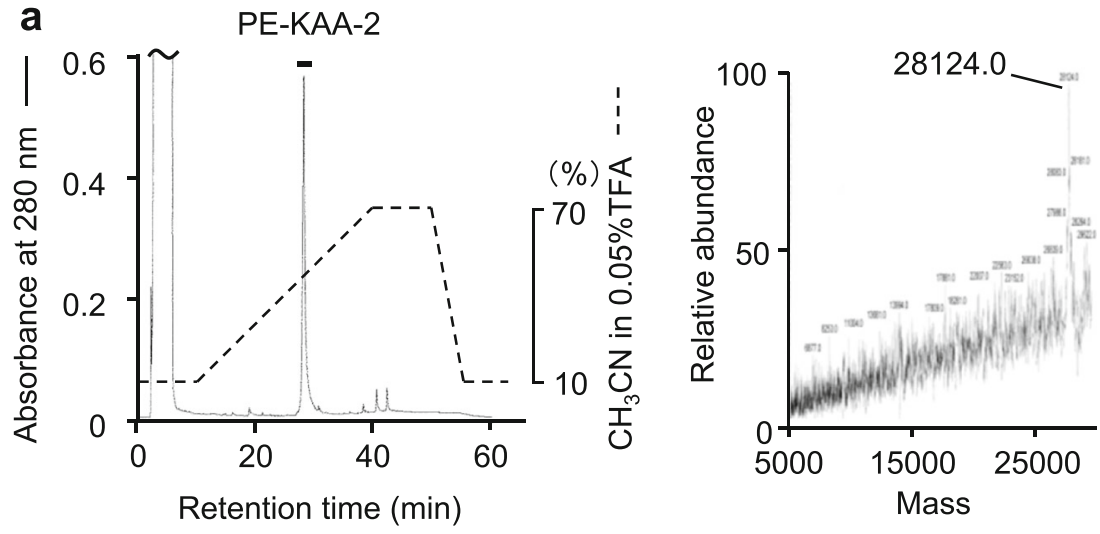

b
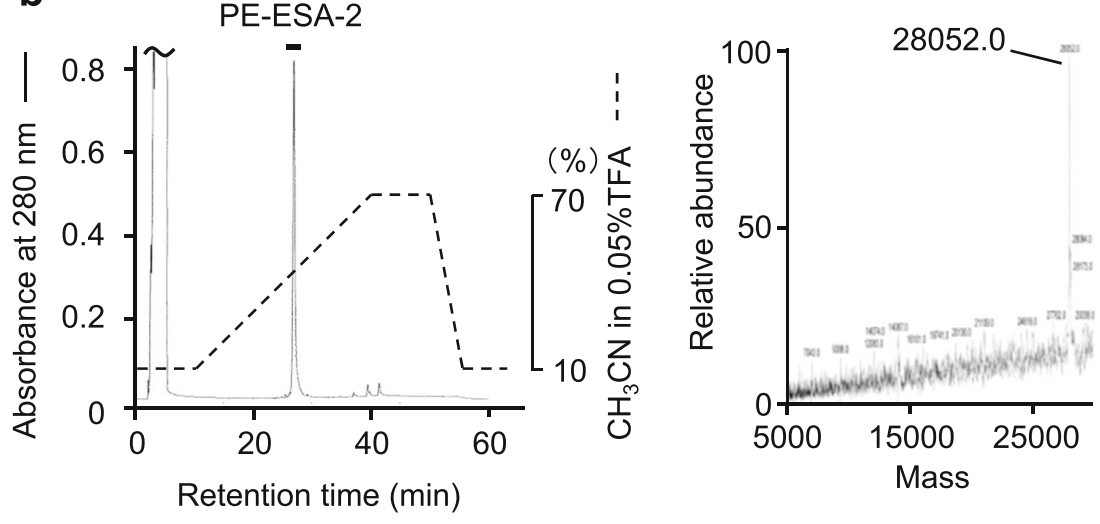

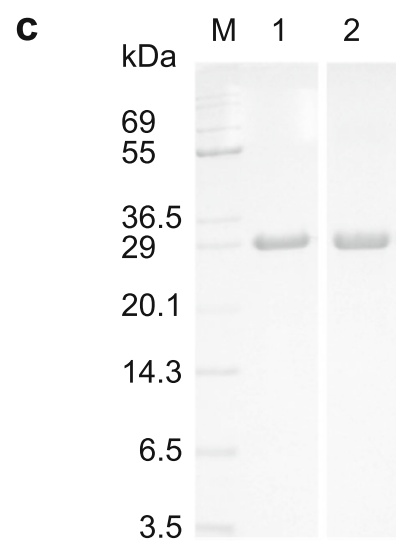


3)Man $\alpha 1-6(\operatorname{Man} \alpha 1-3) \mathrm{Man}-\mathrm{OH})$ which were previously prepared (Hori et al. 2007). A recombinant glycosylated HIV-1 IIIB gp120 (baculovirus) was purchased from ImmunoDiagnostics (MA, USA). Jurkat cells and T lymphocyte-derived cells were propagated in RPMI 1640 medium (Life Technologies) supplemented with $10 \%$ fetal calf serum (Nichirei Biosciences, Tokyo, Japan).

\section{Preparation of S-Pyridylethylated Lectins}

KAA-2 and ESA-2 were subjected to $S$-pyridylethylation according to the method described previously (Hori et al. 2007). $S$-pyridylethylated (PE-) KAA-2 and PE-ESA-2 were purified by reverse-phase (RP-) HPLC on YMC-Pack PROTEIN-RP $(6.0 \times 250 \mathrm{~mm}, \mathrm{YMC}$, Kyoto, Japan). Briefly, after injection of sample to the column equilibrated with $10 \%(\mathrm{v} / \mathrm{v})$ acetonitrile in $0.05 \%(v / v)$ trifluoroacetic acid (TFA), the column was washed with the same solvent for $10 \mathrm{~min}$ and then eluted with a linear gradient (10-70\%) of acetonitrile in $0.05 \%$ TFA for $30 \mathrm{~min}$ at a flow rate of $1.0 \mathrm{ml} / \mathrm{min}$. The eluate was monitored by absorbance at $280 \mathrm{~nm}$ (A280), and the active fractions were recovered. SDS-PAGE for purified proteins was performed using a $15 \%(w / v)$ gel (Schägger and von Jagow 1987).

\section{Trypsin Digestion and Separation of Peptides}

One hundred micrograms each of PE-KAA-2 and PE-ESA-2 were digested with L-1-tosylamido-2-phenylethyl chloromethyl ketone (TPCK)-treated trypsin (Roche Diagnostics, Basel, Switzerland) (enzyme/substrate $=1: 50$ $(w / w))$ in $1 \%(w / v)$ ammonium hydrogen carbonate at $37{ }^{\circ} \mathrm{C}$ for $24 \mathrm{~h}$. For the isolation of peptide fragments, each digest was separated by RP-HPLC on TSKgel ODS-120T column $(4.6 \times 250 \mathrm{~mm}$, Tosoh, Tokyo, Japan). Briefly, the digest was applied to the column equilibrated with $5 \%(v / v)$ acetonitrile in $0.1 \%(v / v)$ TFA. The column was washed with the same solvent for $5 \mathrm{~min}$ and then eluted with a linear gradient $(5-65 \%)$ of acetonitrile in $0.1 \%$ TFA for $60 \mathrm{~min}$ at a flow rate of $1.0 \mathrm{ml} / \mathrm{min}$. The eluate was monitored by absorbance at $220 \mathrm{~nm}$ (A220), and the active fractions were recovered.

\section{Molecular Weight Determination}

The molecular masses of purified PE-KAA-2, PE-ESA-2, and their trypsin-digested peptides were determined by electron spray ionization (ESI)-mass spectrometry (MS) using Finnigan LCQ (Thermo Fisher Scientific, MA, USA). The masses of purified recombinants were determined by ESIMS using LTQ Orbitrap XL (Thermo Fisher Scientific).

\section{N-Terminal Amino Acid Sequencing}

The N-terminal amino acid sequences of PE-KAA-2 and the peptide fragments produced by trypsin digestion of PE-KAA-
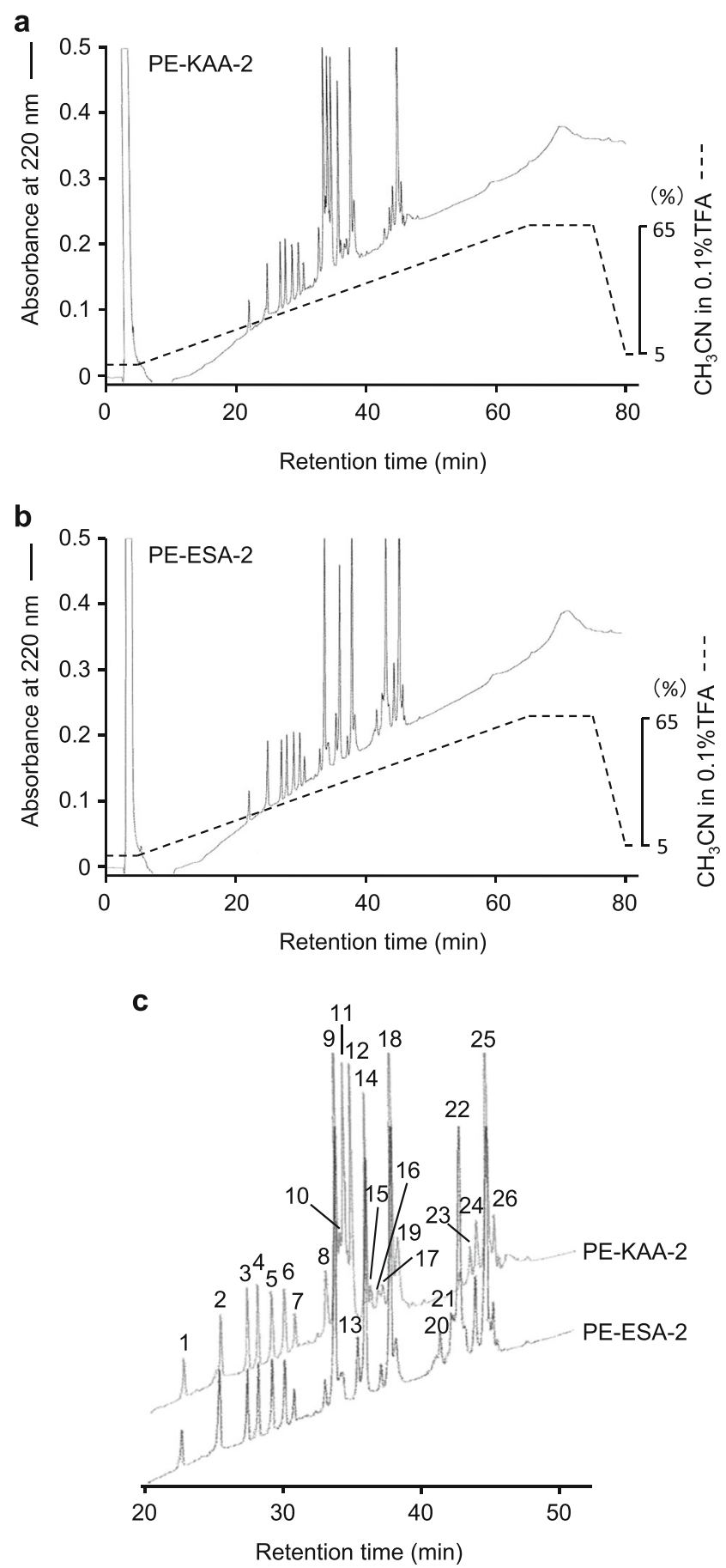

Fig. 3 Peptide fragments generated by trypsin digestion of PE-KAA-2 and PE-ESA-2. Peptide fragments produced by trypsin digestion of PEKAA-2 (a) and PE-ESA-2 (b) were purified by RP-HPLC on TSKgel ODS-120T column, and their enlarged images (c) are shown to compare the peak patterns. The peaks were numbered in serial order of retention time. Peaks 11, 12, 15, 16, and 23, and peaks 13, 20, and 21 were unique for PE-KAA-2 and PE-ESA-2, respectively 
2 were determined by a protein sequencer Procise 492 HT (Life Technologies).

\section{cDNA Cloning of KAAs}

Total RNA was extracted from $2.5 \mathrm{~g}$ of the RNAlater-treated alga of $K$. alvarezii using $25 \mathrm{ml}$ of a Plant RNA Isolation Reagent (Life Technologies). Messenger RNA (mRNA) purification from the total RNA was performed using a NucleoTrap mRNA Purification Kit (Macherey-Nagel, Düren, Germany). Full-length cDNAs were synthesized from $50 \mathrm{ng}$ of a mRNA using GeneRacer Kit (Life Technologies) according to the manufacturer's instruction. The first PCR for rapid amplification of the cDNA $5^{\prime}$ end ( $\left.5^{\prime} \mathrm{RACE}\right)$ was performed with a $50 \mu$ l reaction mixture containing $5 \mu \mathrm{l}$ of $10 \times$ Blend Taq buffer (Toyobo, Osaka, Japan), $10 \mathrm{nmol}$ each of dNTP, 30 pmol of GeneRacer 5' Primer (Life Technologies) (5'-CGACTG GAGCACGAGGACACTGA-3'), 250 pmol of a degenerated primer KAA_5'RACE_R1 (5'-ATIGGICCYTCI CCYTTRTAYTGC- $3^{\prime}$ ), which was designed from the partial amino acid sequence of KAA-2 predicted by peptide mapping, $1 \mu \mathrm{l}$ of 10 -fold diluted synthesized cDNA and $1.25 \mathrm{U}$ of Blend Taq DNA polymerase (Toyobo). Thermal cycling conditions consisted of denaturation at $94{ }^{\circ} \mathrm{C}$ for $3 \mathrm{~min}$, followed by $30 \mathrm{cy}$ cles consisting of denaturation at $94{ }^{\circ} \mathrm{C}$ for $30 \mathrm{~s}$, annealing at $64{ }^{\circ} \mathrm{C}$ for $30 \mathrm{~s}$, and extension at $72{ }^{\circ} \mathrm{C}$ for $1 \mathrm{~min}$, and the final extension step at $72{ }^{\circ} \mathrm{C}$ for $5 \mathrm{~min}$. The nested PCR was performed by the same method, except that $1 \mu \mathrm{l}$ of a 100 -fold

Table 1 The molecular masses of peptide fragments produced by digesting PE-KAA-2 and PE-ESA-2 with trypsin and their corresponding sequence in ESA-2

\begin{tabular}{|c|c|c|c|c|c|}
\hline \multicolumn{2}{|c|}{ PE-KAA-2 } & \multicolumn{3}{|c|}{ PE-ESA-2 } & \multirow[t]{2}{*}{ Sequence in ESA-2 } \\
\hline Peak no. & $\begin{array}{l}\text { Determined } \\
\text { molecular mass }\end{array}$ & Peak no. & $\begin{array}{l}\text { Determined } \\
\text { molecular mass }\end{array}$ & $\begin{array}{l}\text { Calculated } \\
\text { molecular mass }\end{array}$ & \\
\hline 1 & 1023.6 & 1 & 1023.6 & 1024.1 & ${ }^{230} \mathrm{HNQNITAVK}^{238}$ \\
\hline 2 & 1275.4 & 2 & 1275.6 & 1276.3 & ${ }^{247}$ NLDGTCTYER ${ }^{256}$ \\
\hline 3 & 1069.9 & 3 & 1069.5 & 1070.2 & ${ }^{180}$ TLEGTMQYK $^{188}$ \\
\hline 4 & 1171.4 & 4 & 1170.8 & 1172.3 & ${ }^{113}$ TLTGTMTYER $^{122}$ \\
\hline 5 & 746.2 & 5 & 746.3 & 746.9 & ${ }^{123}$ EGPIGFK $^{129 / 257}$ EGPIGFK $^{263}$ \\
\hline 6 & 831.3 & 6 & 831.3 & 831.9 & ${ }^{189}$ GEGPIGFR $^{196}$ \\
\hline 7 & 1588.7 & 7 & 1588.7 & 1589.7 & ${ }^{96}$ SGQGVLAVNITSSDGGK ${ }^{112}$ \\
\hline 8 & 2539.5 & 8 & 2540.7 & 2540.6 & ${ }^{130}$ GTQSGGDTYNVENQWGGSSAPWNK ${ }^{153}$ \\
\hline 9 & 2540.3 & 9 & 2539.5 & 2540.6 & ${ }^{130}$ GTQSGGDTYNVENQWGGSSAPWNK ${ }^{153}$ \\
\hline 10 & 2550.8 & 10 & $\mathrm{ND}^{\mathrm{a}}$ & & \\
\hline 11 & 2364.7 & $-{ }^{\mathrm{b}}$ & & & \\
\hline 12 & 1001.5 & - & & & \\
\hline- & & 13 & 3403.5 & 3402.7 & $\begin{array}{l}{ }^{28} \text { GNQNVMAVDVNSSDGGANLNGTMTYS } \\
\text { GEGPIGFK }^{61}\end{array}$ \\
\hline 14 & 957.4 & 14 & 957.4 & 958.1 & ${ }^{154}$ AGIWALGDR $^{162}$ \\
\hline 15 & 3490.5 & - & & & \\
\hline 16 & $3450.1 \pm 3.96^{\mathrm{c}}$ & - & & & \\
\hline 17 & 3348.2 & 17 & 3348.5 & 3348.6 & ${ }^{65}$ RGESNVYDVENQWGGSSAPWHAGGQFVIGSR ${ }^{95}$ \\
\hline 18 & 3347.3 & 18 & 3347.5 & 3348.6 & ${ }^{65}$ RGESNVYDVENQWGGSSAPWHAGGQFVIGSR ${ }^{95}$ \\
\hline 19 & 3375.3 & 19 & 3375.9 & & \\
\hline- & & 20 & 3293.9 & 3293.5 & ${ }^{199}$ LSGANNYSVENQWGGSSAPWNAAGDWLIGDR $^{22}$ \\
\hline- & & 21 & ND & & \\
\hline 22 & ND & 22 & 3293.0 & 3293.5 & ${ }^{199}$ LSGANNYSVENQWGGSSAPWNAAGDWLIGDR $^{22}$ \\
\hline 23 & $2759.8 \pm 10.99^{\mathrm{c}}$ & - & & & \\
\hline 24 & 2763.3 & 24 & 2763.9 & 2764.0 & 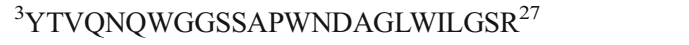 \\
\hline 25 & 2763.2 & 25 & 2763.1 & 2764.0 & 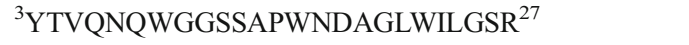 \\
\hline 26 & 2800.2 & 26 & 2796.2 & 2764.0 & 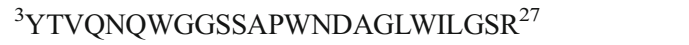 \\
\hline
\end{tabular}

${ }^{\mathrm{a}}$ Not determined

${ }^{\mathrm{b}}$ No consistent peak

${ }^{\mathrm{c}}$ Standard error of $>1.0$ are represented 
diluted solution containing the first PCR product was used as a template, 10 pmol of GeneRacer 5' Nested Primer (5'GGACACTGACATGGACTGAAGGAGTA-3') and 250 pmol of a degenerated primer KAA_5'RACE_R2 (5'-AYT GRTTYTCIACRTTRTAIGTRTC-3') as a primer pair, and that the annealing of the reaction was performed at $58{ }^{\circ} \mathrm{C}$. Nested PCR products were subcloned into pGEM-T Easy vector (Promega). DNA sequencing was performed using BigDye Terminator Cycle Sequencing Kit Ver. 3.1 with ABI 3130xl DNA sequencer (Life Technologies).

3'RACE was performed by the same method of 5'RACE as described above, except that a primer pair of GeneRacer 3' Primer (5'-GCTGTCAACGATACGCTACGTAACG-3') and a degenerated primer KAA_3'RACE_F1 (5'-AYACI TAYAAYGTIGARAAYCARTGGGG-3') for the first PCR and GeneRacer 3' Nested Primer (5'-CGCTACGTAA CGGCATGACAGTG-3') and a degenerated primer KAA_3' RACE_F2 (5' - ARTAYAARGGIGARGGICCIA THGG-3') for the nested PCR were used. At last, the fulllength cDNAs encoding two KAA isolectins were amplified using a high-fidelity DNA polymerase KOD FX Neo (Toyobo) with primer pairs of KAA1_5'End_F (5'TATAGCTGAGTCAAGTTACACCAAC-3') and KAA1_3' End_R (5'-AGAGGGTGATCACGTTTTTAC-3') or KAA2_5'End_F (5'-ACCACCAGCACCGTGCTACT CGCT-3') and KAA2_3'End_R (5'-GAATGTCCTTACG TGGCCTTTAC-3'), which were designed from the $5^{\prime}$ and $3^{\prime}$ terminal sequences of KAA cDNAs obtained by $5^{\prime}$ and $3^{\prime}$ RACEs.

\section{Sequence Data Processing}

Homologous sequences were searched with the basic local alignment search tool (BLAST) program. Amino acid sequence comparison with homologous proteins from various organisms was performed using Clustal Omega (Sievers et al. 2011).

\section{Construction of Expression Vector for Recombinant KAA-1}

The recombinant KAA-1 gene was designed by backtranslation from its amino acid sequence and synthesized by Integrated DNA Technologies (IA, USA). The KAA-1 coding region flanked by the restriction enzyme recognition sites was amplified by means of the PCR using a primer pair of rKAA1_F (5'-GATAGCTAGCGGCCGCTATACAGTT CAAAACC-3') and rKAA1_R (5'-GATCCTCGAGTTAGC TCGCCACGCCTTTAAAG-3'), where underlined nucleotides represent the recognition sites for Nhe I and Xho I, respectively. The PCR using PrimeSTAR HS DNA Polymerase (Takara Bio) consisted of denaturation at $98{ }^{\circ} \mathrm{C}$ for $5 \mathrm{~min}$, followed by 30 cycles consisting of denaturation at $98{ }^{\circ} \mathrm{C}$ for $10 \mathrm{sec}$, annealing at $60{ }^{\circ} \mathrm{C}$ for $5 \mathrm{~s}$, and extension at $72{ }^{\circ} \mathrm{C}$ for $70 \mathrm{~s}$, and the final extension step at $72{ }^{\circ} \mathrm{C}$ for 5 min. An amplified DNA fragment was subcloned into pET-28a(+) (Merck) to yield pET28a-rKAA1, which can express recombinant KAA-1 (rKAA-1) with the N-terminal hexa-His tag followed by the thrombin cleavage site (Fig. 1).

\section{Expression of Recombinant KAA-1}

E. coli SHuffle T7 Express strain (New England Biolabs), which is an enhanced BL21 derivative engineered to express a chromosomal copy of the disulfide bond isomerase DsbC (Chen et al. 1999) in the cytoplasm constitutively, was transformed with the rKAA-1 expression vector pET28a-rKAA1 by a

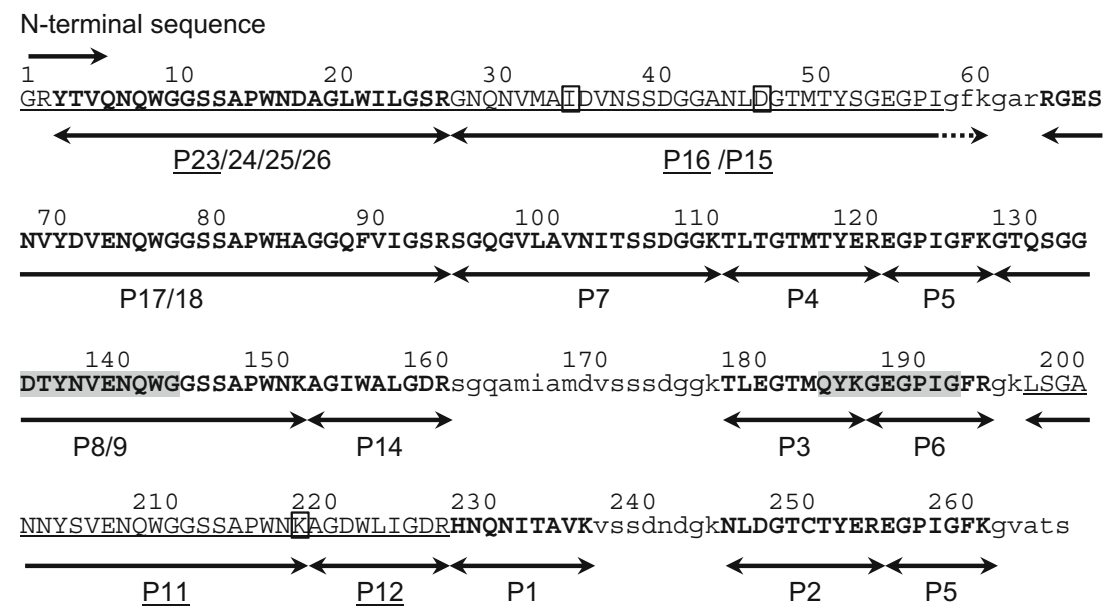

Fig. 4 The predicted amino acid sequence of native KAA-2. The results of sequence prediction by peptide mapping in KAA-2 are shown using ESA-2 sequence as a template. The peptide fragments produced by trypsin digestion of PE-KAA-2 are represented with arrows. The peak numbers examined by Edman degradation and their determined

sequences are underlined. The sequences whose peptide masses were consistent with those of ESA-2 are represented in bold. Unidentified amino acids in KAA-2 are represented as lowercase letter of corresponding sequence in ESA-2. Shaded regions in the sequence were used to design the degenerated primers for cDNA cloning 
conventional method. A transformant was cultured with $1 \mathrm{~L}$ of LB media at $37{ }^{\circ} \mathrm{C}$ until $\mathrm{OD}_{600}$ reached 0.5 , and then, IPTG was added at a final concentration of $0.1 \mathrm{mM}$. After continuously cultured at $20{ }^{\circ} \mathrm{C}$ for $16 \mathrm{~h}$, the bacteria cells were harvested by centrifugation at $10,000 \mathrm{~g}$ for $20 \mathrm{~min}$. After fracturing the cell by sonication, the His-tagged rKAA-1 (His-rKAA-1) expressed into soluble fraction was purified by His GraviTrap (GE Healthcare, Buckinghamshire, UK) according to the manufacturer's instruction. After purification, HisrKAA-1 was dialyzed thoroughly against ultrapure water to remove imidazole which was contained in the elution buffer. Twenty-five milligrams of His-rKAA-1 was then applied to thrombin treatment using a Thrombin Cleavage Capture Kit (Merck) to disconnect the tag peptide from the recombinant according to the manufacturer's instruction. After removal of thrombin by the above kit, the digested fraction was applied to His GraviTrap to exclude the cleaved His-tag peptide and undigested His-rKAA-1. Generated rKAA-1 was then dialyzed thoroughly against ultrapure water.

\section{Measurement of Protein Concentrations}

The A280 of solution was measured with NanoDrop 1000 spectrophotometer (Thermo Fisher Scientific). Crude protein concentrations were represented as A280 at $1.0 \mathrm{mg} / \mathrm{ml}$ is 1.0 . The purified protein concentrations were determined by calculating from A280 and their extinction coefficients which are computed from amino acid sequences (Gill and von Hippel 1989; Pace et al. 1995).
Fig. 5 Nucleotide and deduced amino acid sequences of $K A A-1$. a Nucleotide and deduced amino acid sequences of the cDNA encoding KAA-1. The stop codon is shown as an asterisk. The italicized and nonitalicized numbers represent the positions of nucleotides and amino acids, respectively. Initiating methionine is indicated in italic. The $20 \mathrm{~N}$ terminal amino acid sequence elucidated in Kawakubo et al. (1999) is underlined. $\mathbf{b}$

Comparison among deduced amino acid sequences of $K A A-1$ and $K A A-2$, and the sequence predicted by peptide mapping for native KAA-2 (see Fig. 2).

Lowercase letters in native KAA2 sequence represent the corresponding sequences in ESA2. Amino acid substitutions among KAAs were boxed. The nucleotide sequence data of $K A A$ 1 and $K A A-2$ appear in the DDBJ, EMBL, and GenBank databases under accession number LC007080 and LC007081, respectively

a

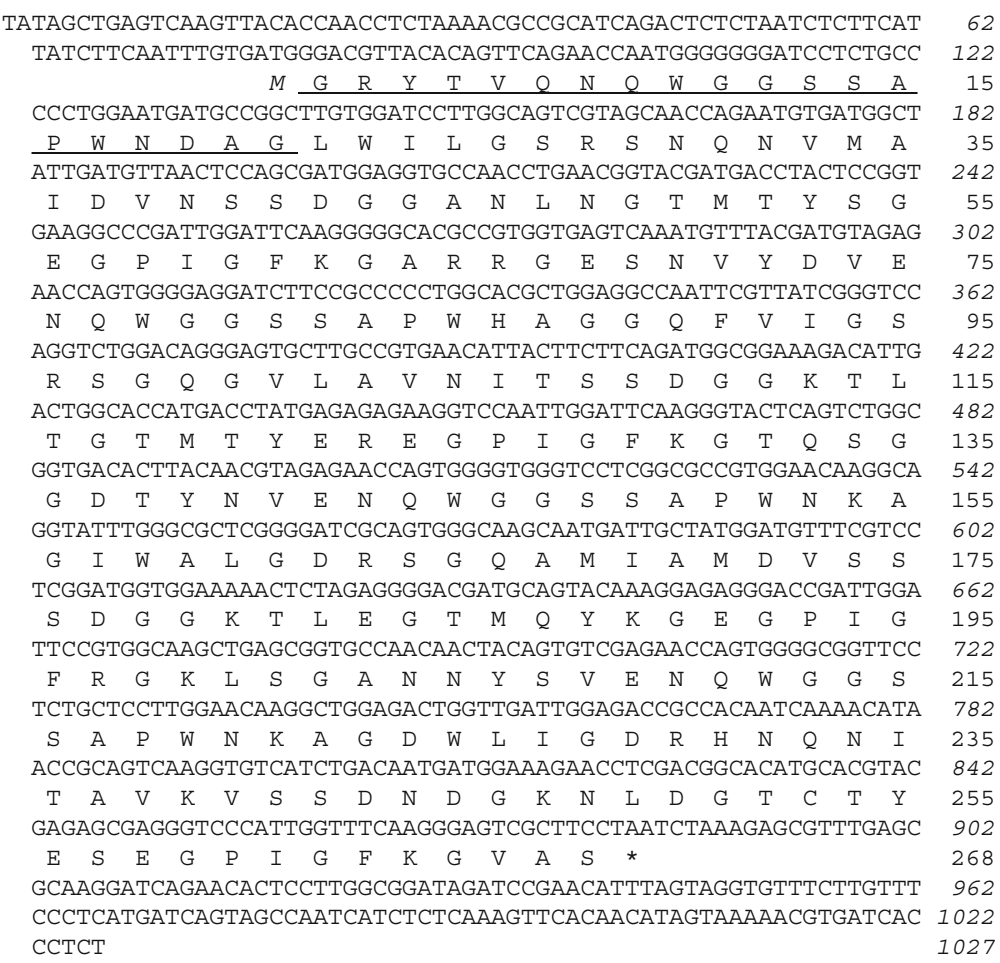

b

mapping

KAA

KAA2

mapping

KAA1

KAA2

mapping

KAA1

KAA2

mapping

KAA1

KAA2

mapping

KAA1
GRYTVQNQWGGSSAPWNDAGLWILGSRGNQNVMAIDVNSSDGGANLDGTMTYSGEGPIgf 60 GRYTVQNQWGGSSAPWNDAGLWILGSR SNQNVMAIDVNSSDGGANLNGTMTYSGEGPIGF 60 GRYTVQNQWGGSSAPWNDAGLWILGSRGNQNVMAIDVNSSDGGANLNGTMTYSGEGPIGF 60

kgarRGESNVYDVENQWGGSSAPWHAGGQFVIGSRSGQGVLAVNITSSDGGKTLTGTMTY 120 KGARRGESNVYDVENQWGGSSAPWHAGGQFVIGSRSGQGVLAVNITSSDGGKTLTGTMTY 120 KGARRGDSNVYDVENQWGGSSAPWHAGGQFVIGSRSGQGVLAVNITSSDGGKTLTGTMTY 120

EREGPIGFKGTQSGGDTYNVENQWGGSSAPWNKAGIWALGDRsgqamiamdvsssdggkt 180 EREGPIGFKGTQSGGDTYNVENQWGGSSAPWNKAGIWALGDRSGQAMIAMDVSSSDGGKT 180 EREGPIGFKGTQSGGDTYNVENQWGGSSAPWNKAGIWALGDRSGQAMIAMDVSSSDGGKT 180

LEGTMQYKGEGPIGFRgkLSGANNYSVENQWGGSSAPWNKAGDWLIGDRHNQNITAVKVS 240 LEGTMQYKGEGPIGFRGKLSGANNYSVENQWGGSSAPWNKAGDWLIGDRHNQNITAVKVS 240 LEGTMQYKGEGPIGFRGKLSGANNYSVENQWGGSSAPWNKAGDWLIGDRHNQNITAVKVS 240

sdndgkNLDGTCTYEREGPIGFKgvats 268 SDNDGKNLDGTCTYESEGPIGFKGVAS- 267 SDNDGKNLDGTCTYEREGPIGFKGVATS 268 


\section{Hemagglutination Assay and Hemagglutination Inhibition Test}

Hemagglutination assay was performed using a $2 \%(v / v)$ suspension of trypsin-treated rabbit erythrocytes (TRBCs) as described previously (Hori et al. 1986). Hemagglutination activity was expressed as a titer, the reciprocal of the highest 2-fold dilution exhibiting positive hemagglutination. Hemagglutination-inhibition assay was also performed using a $2 \%(v / v)$ suspension of TRBC and following sugars and glycoproteins as described in Hori et al. (1986); D-glucose, Dgalactose, D-mannose, D-xylose, $N$-acetylglucosamine, $N$ acetylgalactosamine, $N$-acetylneuraminic acid, L-fucose, Lrhamnose, lactose, transferrin (human), asialo-transferrin, fetuin (type III, fetal calf serum), asialo-fetuin, yeast mannan, porcine thyroglobulin (PTG), asialo-PTG, bovine submaxillary mucin (BSM), and asialo-BSM. The inhibitory activity was expressed as the minimum concentration of sugar (mM) or glycoprotein $(\mu \mathrm{g} / \mathrm{ml})$ that completely inhibited the activity of a lectin solution of hemagglutination titer 8 .

\section{Centrifugal Ultrafiltration-HPLC Method for Determining Oligosaccharide Binding Specificity of rKAAs}

The oligosaccharide binding activity of rKAAs was determined by a centrifugal ultrafiltration-HPLC method as described in Hori and Hirayama (2014). Briefly, $90 \mu \mathrm{l}$ of $500 \mathrm{nM}$ His-rKAA-1 or rKAA-1 in $50 \mathrm{mM}$ Tris- $\mathrm{HCl}$ (pH7.0), and $10 \mu \mathrm{l}$ of $300 \mathrm{nM}$ PA-oligosaccharide were mixed and kept at room temperature for $60 \mathrm{~min}$. Subsequently, unbound PA-oligosaccharides were collected by centrifugation $(10,000 g, 30 \mathrm{~s})$ using Nonosep $10 \mathrm{~K}$ Device (Pall, NY, USA). An aliquot of the filtrate was applied to a TSKgel ODS 80TM column $(4.6 \times 150 \mathrm{~mm}$, Tosoh), and unbound PAoligosaccharide was quantified from the peak area. The amount of bound PA-oligosaccharide was obtained by subtracting the amount of unbound oligosaccharide from the amount of added oligosaccharide, which was determined from the filtrate of the reaction solution without a lectin. The binding activity (\%) was calculated as the ratio of the amount of bound oligosaccharide to that of added oligosaccharide.

\section{Surface Plasmon Resonance Analysis of Interaction of KAAs with HIV Envelope Protein gp120}

Interaction of KAAs, including His-rKAA-1, rKAA-1, KAA1, and KAA-2, with the HIV envelope gp120 was analyzed by surface plasmon resonance (SPR) analysis using a BIAcore 2000 system (GE Healthcare) as described previously (Sato et al. 2007, 2011b). The recombinant glycosylated HIV-1 IIIB gp120 (baculovirus) was immobilized to give 300 resonance units on a carboxymethylated dextran-coated sensor chip (CM5, GE Healthcare). Ninety microliters of each concentration of His-rKAA-1 and rKAA-1 solution (0.98, 3.9, 7.8, and $15.6 \mathrm{nM}$ ) was injected into the flow cells at $30 \mu \mathrm{l} / \mathrm{min}$ for $3 \mathrm{~min}$ to observe the association, and then, the same amount of the running buffer HBS EP (GE Healthcare) was injected into the flow cells at $30 \mu \mathrm{l} / \mathrm{min}$ for $3 \mathrm{~min}$ to observe the dessociation. The data of rKAAs were fit globally to a simple

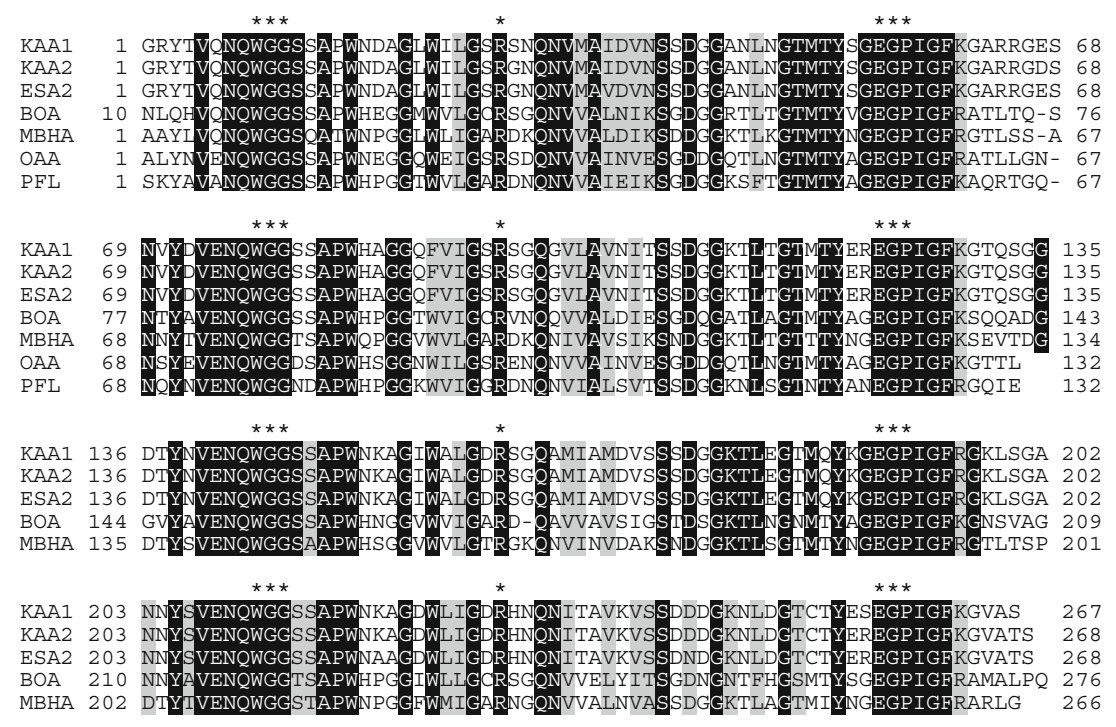

Fig. 6 Alignment of amino acid sequences from KAAs and related proteins. Identical and similar residues among all proteins are indicated with black and gray backgrounds, respectively. Amino acids that interact with mannopentaose (Man $\alpha 1-6(\operatorname{Man} \alpha 1-3) \operatorname{Man} \alpha 1-6(\operatorname{Man} \alpha 1-3)$ Man) of M8/9 core unit in Burkholderia oklahomensis agglutinin (BOA) are indicated with asterisks. Data were cited from the following: Eucheuma serra agglutinin-2 (ESA-2, GenBank accession no. P84331), Burkholderia oklahomensis agglutinin (BOA, AIO69853), Myxococcus xanthus agglutinin (myxobacterial hemagglutinin (MBHA), M13831), Oscillatoria agardhii agglutinin (OAA, P84330), and Pseudomonas fluorescens lectin (PFL, ABA72252) 
Langmuir 1:1 binding model with local $\mathrm{R}_{\max }$ (maximum response) using BIAevaluation 3.1 software. For KAA-1 and KAA-2, lectin solutions of $0.98 \mathrm{nM}$ were applied to the system and the obtained sensorgrams were compared with those of the recombinants at same concentration to evaluate the functional similarities among the natives and recombinants.

\section{Anti-HIV Activity}

The HIV-1 virus stock was prepared from the Jurkat cells transfected with an HIV-1 genome-encoding plasmid, pNL43 , originally constructed from the NY5 and RAV proviruses (Adachi et al. 1986). Infectivity of HIV-1 was measured with the median tissue culture infectious dose $\left(\mathrm{TCID}_{50}\right)$ method using Jurkat cells. HIV-1 $\left(100 \mathrm{TCID}_{50}\right)$ was incubated with 2-fold serially diluted lectins, in which their final concentrations were from $1 \mu \mathrm{M}$ to $1 \mathrm{nM}$, at room temperature for $3 \mathrm{~min}$ in four or eight wells of a 96-well plate for each dilution. Jurkat cells $\left(5 \times 10^{4}\right.$ cells/well $)$ were further added and incubated for several days until cytopathic effects developed. Fifty percent endpoint of lectin concentration to neutralize virus infectivity was determined according to the Behrens-Kaerber method, and $50 \%$ inhibitory concentration $\left(\mathrm{IC}_{50}\right)$ was determined. Cell viability in the presence of lectins was examined by using the Cell Proliferation Kit I (MTT assay; Roche Diagnostics, Tokyo, Japan).

\section{Results}

\section{Peptide Mapping of KAA-2}

Before peptide mapping, KAA-2 and ESA-2 were pyridylethylated and then purified as single peaks by RPHPLC on YMC-Pack PROTEIN-RP column (Fig. 2a, b). The molecular masses of PE-KAA-2 and PE-ESA-2 were determined to be $28,124.0$ and $28,052.0$ by ESI-MS. These values were consistent with those estimated by SDS-PAGE (Fig. 2c). Peptide fragments generated by trypsin digestion of PE-KAA-2 and PE-ESA-2 were separated into a total of 26 peaks, including 18 common peaks between both, 5 specific peaks in PE-KAA-2, and 3 specific peaks in PE-ESA-2, by RP-HPLC on TSKgel ODS 120T (Fig. 3, Table 1). The molecular masses of the isolated peptide fragments were determined by ESI-MS, except for a peak 22 in PE-KAA-2 and peaks 10 and 21 in PE-ESA-2. The determined masses were compared to those of the peptide fragments that are theoretically generated by trypsin digestion of PE-ESA-2 (Table 1). All peptides whose masses were successfully determined were found in the PE-ESA-2 sequence, except for a peak 19, mass of which was not found in both sequences of PE-ESA-2 and trypsin used for digestion. The sequence of 167 amino acids (aa) of PE-KAA-2 was successfully predicted by comparing the sequences of 18 peptides with the same masses, which were commonly generated from both PE-KAA-2 and PEESA-2. Moreover, the N-terminal sequencing of the specific peptide peaks $(11,12,15,16$, and 23) from PE-KAA-2 showed that there are at least 3 amino acid substitution for PE-ESA-2 (Fig. 4). The peptide sequence of a peak 10 (determined MW 2550.8) in PE-KAA-2 could be an incompletely digested product of ${ }^{197}$ GKLSGANNYSVENQWGG SSAPWNK $^{220}$ (calculated MW 2551.7). Thus, a total of 230 aa in the whole sequence of PE-KAA-2 was successfully predicted by peptide mapping.
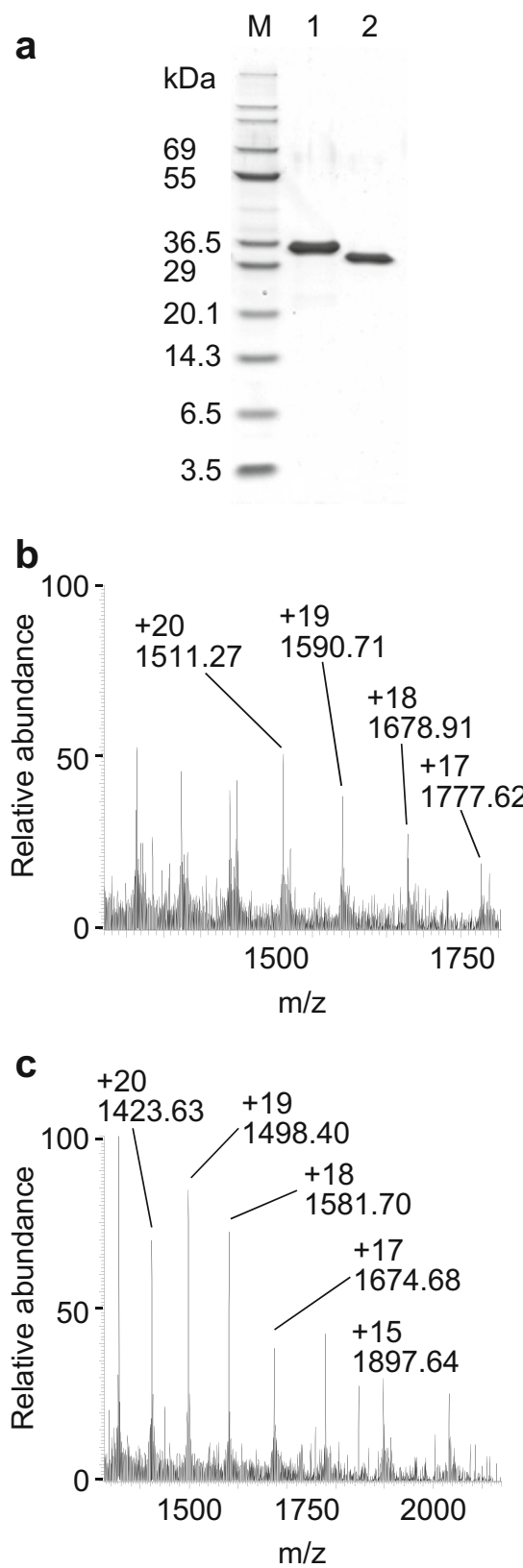

Fig. 7 Preparation of rKAAs. a Nonreducing SDS-PAGE for purified His-rKAA-1 (lane 1) and rKAA-1 (lane 2). Five micrograms of each protein was loaded. $M$ molecular weight marker. ESI-MS multiply charged spectra of purified His-rKAA-1 (b) and rKAA-1 (c) were shown 


\section{Nucleotide and Amino Acid Sequences of KAAs}

cDNA cloning by RACE methods resulted in isolation of two full-length cDNAs encoding KAA isoforms (Fig. 5). Compared the deduced amino acid sequences of the two isoforms and the partial sequence of KAA-2 predicted by peptide mapping, it was found that there are substitutions of a few amino acids to one another, further indicating that KAA-2 isolated from the cultivated alga was not encoded by the two cloned cDNAs. This may be attributed to the difference of algal samples used for lectin isolation and cDNA cloning. Here, we defined the isolectin cDNA whose deduced amino acid sequence was closer to the predicted KAA-2 by peptide mapping as $K A A-2$ (DDBJ/EMBL/GenBank accession no. LC007081) and the other as KAA-1 (LC007080) (Fig. 5). KAA-1 cDNA was composed of 1027 bp containing $77 \mathrm{bp}$ of 5' untranslated region (UTR), $143 \mathrm{bp}$ of 3'UTR, and $807 \mathrm{bp}$ of open reading frame (ORF) which encoded 268 amino acids including an initiating methionine. KAA-2 cDNA was composed of $1161 \mathrm{bp}$ containing $94 \mathrm{bp}$ of 5'UTR, $257 \mathrm{bp}$ of $3^{\prime}$ UTR, and $810 \mathrm{bp}$ of ORF encoding 269 amino acids including an initiating methionine (LC007081). The predicted Nterminal amino acid sequence of the mature KAAs was completely comparable in the sequence determined by Edman degradation for PE-KAA-2 (underlined sequence in Fig. 5a), indicating that KAA cDNAs do not encode signal peptide and other propeptide regions. These two KAAs showed 89.7 and $98.5 \%$ identities to each other in nucleotide and protein levels, respectively. Amino acid sequence identities between ESA-2 and KAA-1 or KAA-2 are 98.1 and $98.9 \%$, respectively. KAAs also contain four tandem repeats of around 67 amino acids (Fig. 6) as well as ESA-2 (Hori et al. 2007). These repeated sequences are highly conserved between one another and among related proteins from other organisms including bacteria (Burkholderia oklahomensis agglutinin (BOA, 4 repeats), Myxococcus xanthus agglutinin (MBHA, 4 repeats), Pseudomonas fluorescens lectin (PFL, 2 repeats)) and cyanobacteria (O. agardhii (OAA, 2 repeats)) (Fig. 6). Similar sequence was not found in higher plants or animals by BLAST search. The sequence identities between KAA-1 and BOA, MBHA, OAA, or PFL were 58.1, 60.2, 60.6, and $62.9 \%$, respectively. The amino acids that interact with mannopentaose (Man $\alpha 1-6(\operatorname{Man} \alpha 1-3) \operatorname{Man} \alpha 1-6(\operatorname{Man} \alpha 1-3)$ Man), which is a branched oligomannosyl core structure of M8/9, in BOA (Koharudin et al. 2012) are absolutely conserved in all repeated domains of the lectins (indicated with asterisks in Fig. 6).

\section{Preparation of Active Form of Recombinant KAA-1}

His-rKAA-1 was successfully generated using pET system and a SHuffle T7 Express strain (Fig. 7). His-rKAA-1 was prepared in the yield of $115 \mathrm{mg}$ per $11 \mathrm{LB}$ media, and rKAA-1 was generated in the yield of $15 \mathrm{mg}$ from $25 \mathrm{mg}$ of His-rKAA-1. The molecular masses of His-rKAA-1 and
Table 2 Hemagglutinationinhibition test of native and recombinant KAAs with sugar compounds

\begin{tabular}{|c|c|c|c|c|}
\hline \multirow[t]{2}{*}{ Sugars and glycoproteins } & \multicolumn{4}{|c|}{ Minimum inhibition concentration } \\
\hline & KAA-1 & KAA-2 & His-rKAA-1 & rKAA-1 \\
\hline Monosaccharides and disaccharide $(\mathrm{mM})^{\mathrm{a}}$ & $>100$ & $>100$ & $>100$ & $>100$ \\
\hline \multicolumn{5}{|l|}{ Glycoproteins (mg/ml) } \\
\hline \multicolumn{5}{|l|}{$N$-glycan type } \\
\hline \multicolumn{5}{|l|}{ High-mannose type } \\
\hline Yeast mannan & 31.3 & 62.5 & 31.3 & 62.5 \\
\hline \multicolumn{5}{|l|}{ High-mannose and complex types } \\
\hline Porcine thyroglobulin (PTG) & 15.6 & $<7.8$ & 15.6 & 31.3 \\
\hline Asialo-PTG & $<7.8$ & $<7.8$ & $<7.8$ & 15.6 \\
\hline \multicolumn{5}{|l|}{ Complex type } \\
\hline Transferin & $>1000$ & $>1000$ & 1000 & $>1000$ \\
\hline Asialo-transferin & 500 & 250 & 250 & 500 \\
\hline \multicolumn{5}{|l|}{$\mathrm{N} / \mathrm{O}$-glycan type } \\
\hline Fetuin & $>1000$ & $>1000$ & $>1000$ & $>1000$ \\
\hline Asialo-fetuin & 250 & 250 & 250 & 500 \\
\hline \multicolumn{5}{|l|}{$O$-glycan } \\
\hline Bovine submaxirally mucin (BSM) & 62.5 & 125 & 125 & 250 \\
\hline Asialo-BSM & 31.3 & 31.3 & 62.5 & 125 \\
\hline
\end{tabular}

${ }^{a}$ Monosaccharides (100 mM) (Glc, Man, Gal, GlcNAc, GalNAc, Rha, Fuc, Xyl, NeuAc) and a disaccharide (lactose) did not inhibit hemagglutination activities of four lectins 
rKAA-1 were calculated as 30,202.7 and 28,451.9, respectively, based on their amino acid sequences. Although the recombinants ran at about $30-35 \mathrm{kDa}$ in SDS-PAGE (Fig. 7a), the molecular masses determined by ESI-MS, 30, 203.7 Da for His-rKAA-1 (Fig. 7b) and 28,452.1 Da for rKAA-1 (Fig. 7c), were in good agreement with the calculated ones. Hemagglutination actvities of His-rKAA-1 and rKAA-1 (each $10 \mu \mathrm{M}$ ) were $2^{12}$ with TRBC as well as those of native KAA-1 and KAA-2 (data not shown).

\section{Carbohydrate and Oligosaccharide Binding Specificity of rKAAs}

Hemagglutination inhibition test revealed that the recombinants (His-rKAA-1 and rKAA-1) and native KAA-1 and KAA-2 preferentially bound to glycoproteins containing high-mannose-type $N$-glycans such as yeast mannan and PTG, and weakly to the other glycoproteins without highmannose $\mathrm{N}$-glycan (Table 2). They had not affinity for any monosaccharide examined, including mannose. A relatively strong binding to BSM and asialo-BSM with $O$-glycans was also observed for the recombinants and native KAAs. Thus, the hemagglutination inhibition profiles of the recombinant KAAs were consistent with those of native KAAs, regardless of the presence or absence of the His-tag peptide in its $\mathrm{N}$-terminus.

In oligosaccharide binding experiments by a centrifugal ultrafiltration-HPLC method with 27 PA-sugars (Figs. 8 and 9), His-rKAA-1 and rKAA-1 strongly bound to five oligosaccharides (oligosaccharides 7, 8, 10,12 and 15) belonging to high-
Fig. 8 Structures of PAoligosaccharides used in this study. Closed circle, galactose; open circle, mannose; closed triangle, glucose; open triangle, fucose; closed square, $N$ acetylglucosamine; open square, $\mathrm{N}$-acetylgalactosamine; closed diamond, $N$-acetylneuraminic acid

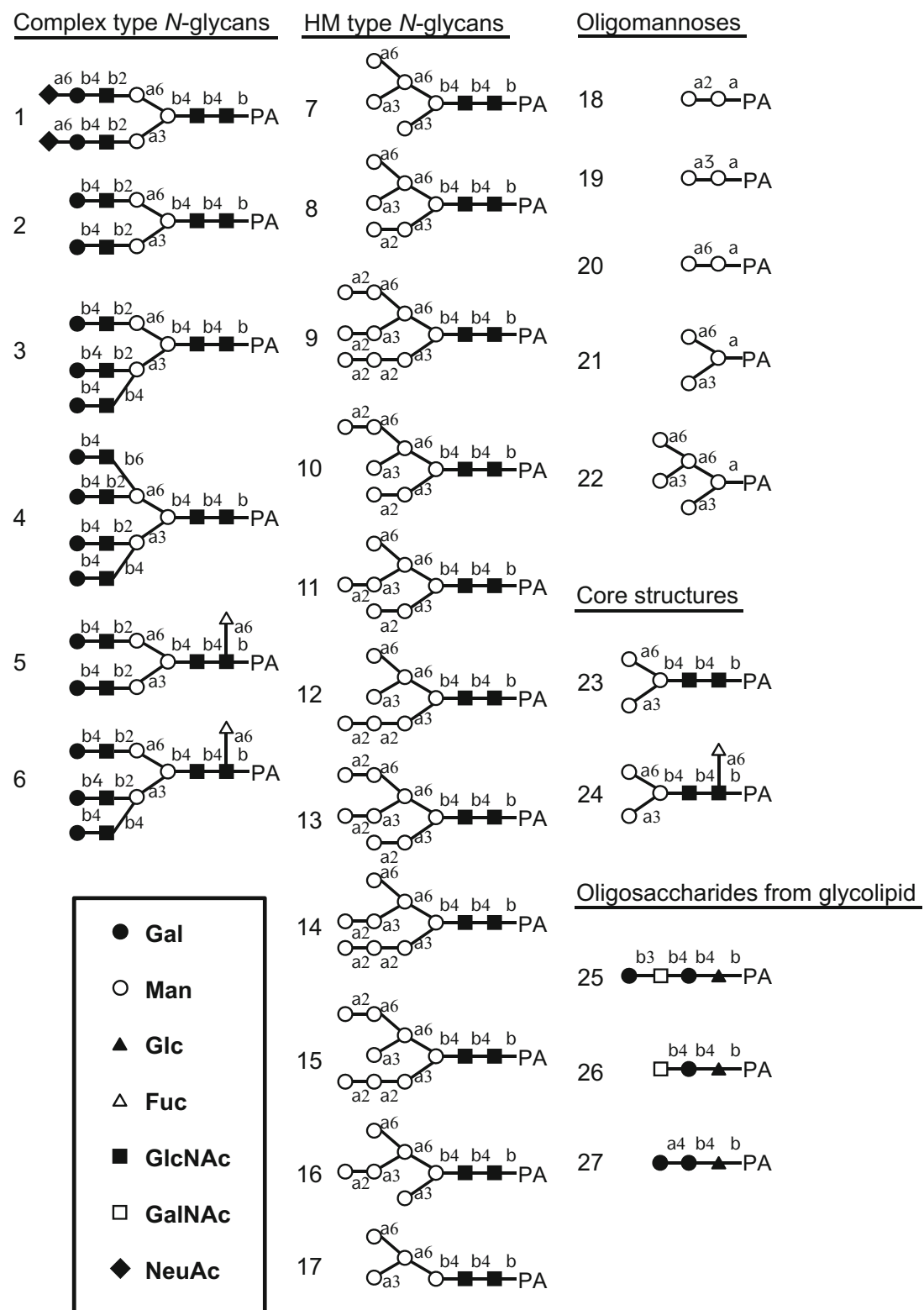


mannose-type $N$-glycans (oligosaccharides 7-17), but hardly to complex type $N$-glycans (oligosaccharides 1-6), oligomannoses (oligosaccharides 18-22), core structures (oligosaccharides 23 and 24), or oligosaccharides from glycolipids (oligosaccharides 25-27) (Fig. 9). Comparing the binding activities between oligosaccharides $7(80.8 \%$ in HisrKAA- 1$)$ and $16(17.1 \%), 8(100 \%)$ and $11(19.3 \%), 10$ $(100 \%)$ and $13(20.7 \%), 12(95.6 \%)$ and $14(36.7 \%)$, or 15 $(100 \%)$ and $9(12.7 \%)$ revealed that rKAAs recognized the nonreducing terminal $\alpha 1-3$ linked Man of the D2 arm of branched oligomannoside, and the nonreducing terminal $\alpha 1$ 2 linked Man in the D2 arm negatively affects for binding of rKAAs. The presence of His-tag hardly influenced to the oligosaccharide binding preferences of the recombinants although His-rKAA-1 and rKAA-1 were approximately $35 \%$ apart in binding activities to oligosaccharides 7 and 17 .

\section{Interaction of rKAAs with a Recombinant HIV Envelope Glycoprotein gp120}

Interaction between rKAAs and HIV envelope glycoprotein gp120 was performed by SPR analysis using BIAcore 2000 system. His-rKAA-1 and rKAA-1 bound to the gp120 immobilized on the chip dose-dependently (Fig. 10a, b) and binding kinetics of the interactions was well fitted to each sensorgram (overlaid red lines in Fig. 10a, b). rKAAs (Fig. 10a, b) showed high association constants $\left(\mathrm{K}_{\mathrm{A}}\right)(1.48-$ $\left.1.61 \times 10^{9} \mathrm{M}^{-1}\right)$ and low dessociation constants $\left(\mathrm{K}_{\mathrm{D}}\right)$ in the picomolar range $\left(6.22-6.77 \times 10^{-10} \mathrm{M}\right)$ to HIV gp120, regardless of presence of His-tag (Table 3 ). The sensorgrams of KAAs including His-rKAA-1, rKAA-1, KAA-1, and KAA2 at same concentration of $0.98 \mathrm{nM}$ were very similar as shown in Fig. 10c. Although the resonance unit of the sensorgram in His-rKAA-1 appeared slightly higher than those of the other KAAs, it might be caused by the molecular weight difference, because the molecular weight of HisrKAA-1 having N-terminal His-tag peptide is approximately 2000 Da higher than those of the other KAAs.

\section{Anti-HIV Activities of KAAs}

In vitro anti-HIV activities of His-rKAA-1, KAA-1, and KAA-2 against HIV-1 strain (derived from pNL4-3) in Jurkat cells were determined by a neutralization assay. Serially diluted lectins and HIV-1 were reacted for 3 min at room temperature, and then, Jurkat cells were added and further incubated until cell fusion fully developed. Experiments were repeated at least three times for each lectin. Cell viability of Jurkat cells without HIV-1 was not affected by the same concentrations of lectins as judged by the MTT assay (data not shown). The results showed that KAAs prevented infection of HIV-1 at low nanomolar $\mathrm{IC}_{50}$ of 12.9, 9.2, and $7.3 \mathrm{nM}$ for HisrKAA-1, KAA-1, and KAA-2, respectively (Table 4).
Fig. 9 Interaction analysis between rKAAs and various oligosaccharides by a centrifugal ultrafiltration-HPLC method. a Binding activities of rKAAs to PA-oligosaccharides. Binding activity was expressed as a ratio (\%) of the amount of a bound oligosaccharide to that of an added oligosaccharide. The assay was performed in duplicate for each PA-oligosaccharide, and the activity is expressed as the average value from duplicate assays. The activities less than $10 \%$ were cut off for their insignificance. $\mathbf{b}$ The detailed binding activities of rKAAs with high-mannose-type $N$-glycans. Dashed boxes represent the nonreducing terminal $\alpha 1-2$ linked mannose residue in the D2 arm

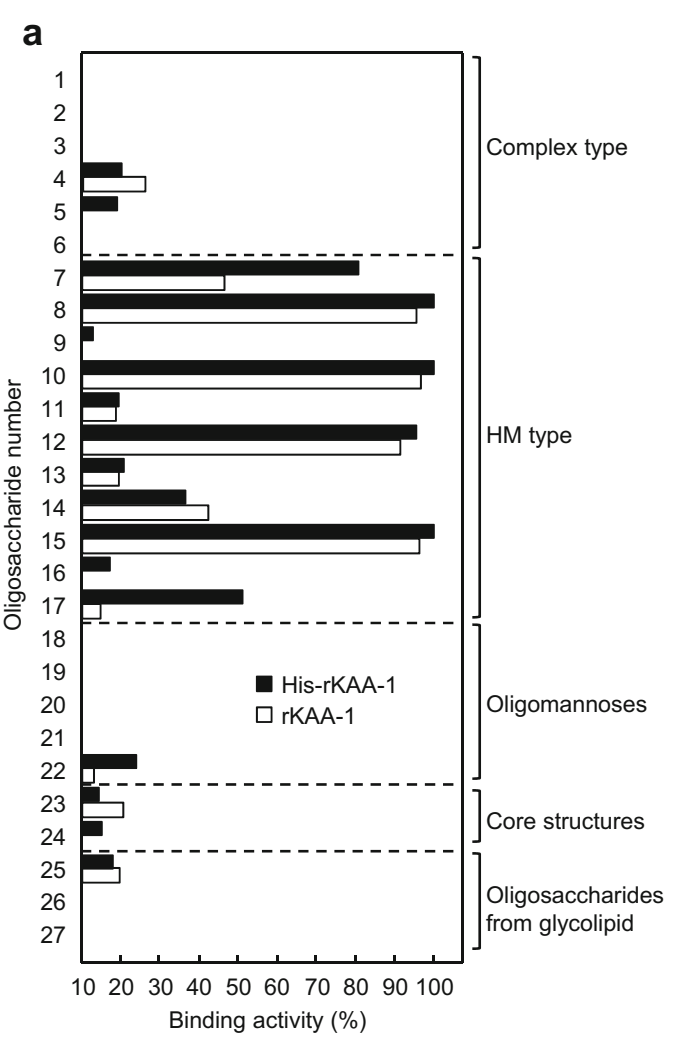

b

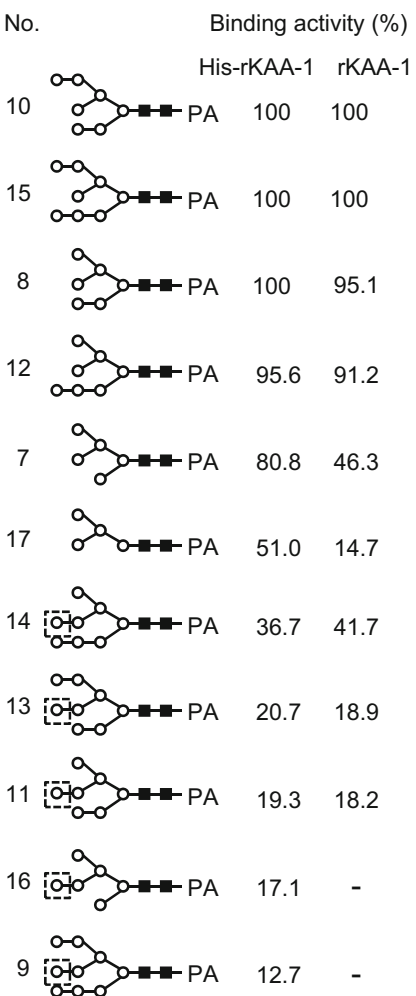




\section{Discussion}

Since Kawakubo et al. (1999) reported that the N-terminal amino acid sequences of KAAs were identical to those of ESAs, the whole primary structure of KAA-2 was considered to have high similarity with that of ESA-2. Peptide mapping of KAA-2 using the sequence of ESA-2 as a template has elucidated $85 \%(230 / 268$ aa) of the full-length sequence. A calculated molecular mass of the predicted sequence by peptide mapping, including the corresponding sequences of ESA2, was 28,022, which gave close agreement with that of PEKAA-2 (28,124 including an $S$-pyridylethyl group (105 Da) (Fig. 2a)). Although cDNA cloning by RACE method elucidated the full length cDNAs encoding KAAs, both of their deduced amino acid sequences were not identical to that of the native KAA-2 predicted by peptide mapping (Fig. $5 b$ ). The calculated molecular mass from their sequences were 27, 881.24 and 28,007.41, respectively, and were also inconsistent with that of native KAA-2. We defined one of the two KAA cDNAs as $K A A-2$, whose amino acid sequence was more similar to native KAA-2 and ESA-2, and the other as $K A A-1$. The slight sequence differences between native KAA- 2 and deduced KAA-2 might be individual variability in algal samples used. cDNA cloning has also elucidated that the transcripts of $K A A$ s do not contain the region encoding a signal peptide sequence (Fig. 5), which target the proteins from the cytosol to the cytoplasmic membrane (prokaryotes) or to the endoplasmic reticulum membrane (eukaryotes) (Imai and Nakai 2010), as well as that of $O A A$ from a cyanobacterium does not (Sato and Hori 2009). It has reported that cDNAs encoding a lectin from Euonymus europaeus (EEA) and EUL protein from Arabidopsis thaliana (ArathEULS3) do not encode a signal peptide and these translated product located in the nucleus and cytoplasm (Van Hove et al. 2011) as well as a GNA ortholog from rice that lacks the signal peptide and propeptide sequence (Fouquaert et al. 2007). In addition, there are not any known cellular localization signals in the primary structure of KAAs (data not shown). It suggests that KAAs are also synthesized on free ribosomes and located in nucleocytoplasm. There is only a report as to the cellular localization of KAA orthologs; Nelson et al. (1981) reported that MBHA, a KAA ortholog from a myxobacterium, localizes at the specific sites on the surface of developmental cells but not vegetated cells and suggested their function in cellular interactions during aggregation. Detailed cellular localization of KAA should be elucidated and will help to predict their functions in the algal bodies.

KAAs contain four tandem repeat domains in a molecule (Fig. 6). All the lectins of this family from algae are supposed to compose of four tandem repeat domains commonly, contrary to those from cyanobacteria and bacteria; in cyanobacteria, OAA composes of two repeats (Sato et al. 2007; Sato and Hori 2009) and a hypothetical protein from
Lyngbya sp. (accession no. ZP 016222182) does four repeats (Sato and Hori 2009); in bacteria, PFL composes of two repeats (Sato et al. 2012) and BOA (Whitley et al. 2013) and MBHA (Koharudin et al. 2012) do four repeats (Fig. 6). Interestingly, several amino acid residues ( 23 aa per a single repeat domain) are absolutely conserved in all the domains among seven lectins shown in Fig. 6. The amino acid residues (7 aa per a single repeat domain) which interact with mannopentaose of a branched oligomannosyl core of M8/9 in BOA (Whitley et al. 2013) are also conserved (Fig. 6). This structural kinship suggested that lectins belonging to this
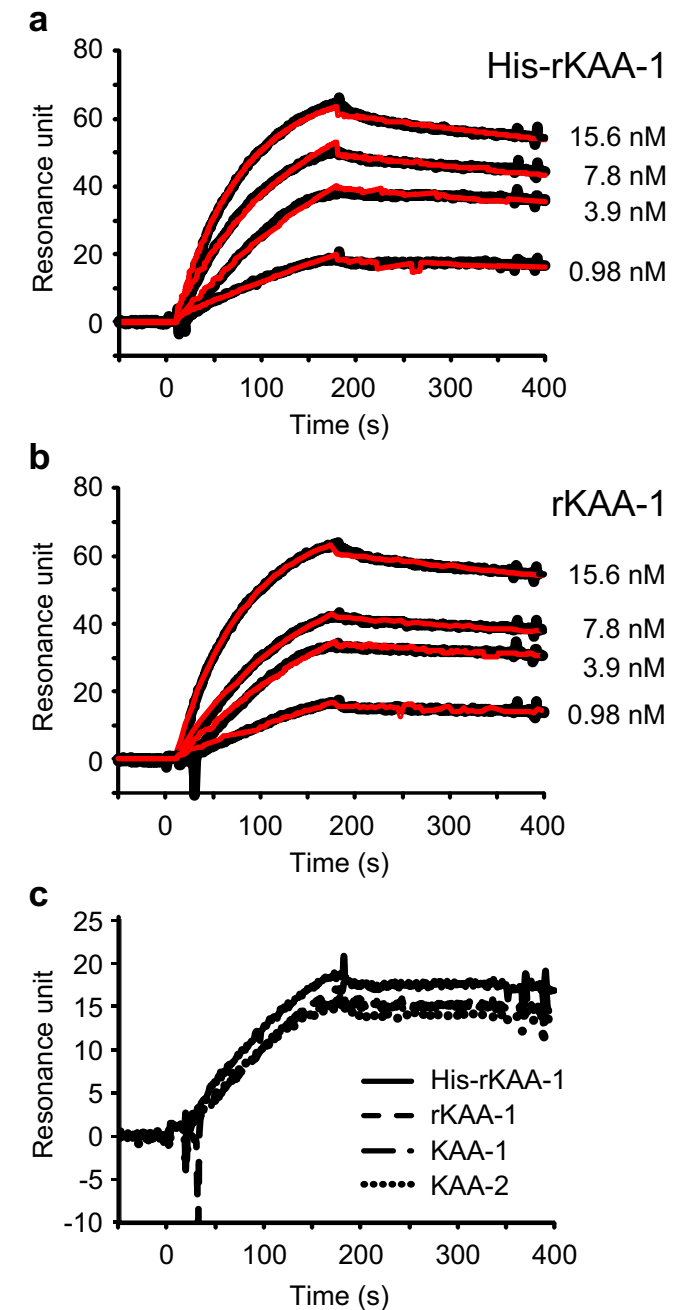

Fig. 10 Interaction of KAAs with an HIV envelope glycoprotein gp120. SPR analyses for interaction between gp120 and His-rKAA-1 (a) or rKAA-1 (b) were analyzed with BIAcore2000. Each sensorgram represents the binding activity of rKAAs to gp120 on sensor chip. Ninety microliters of rKAAs solutions of each represented concentration were injected into the flow cells at $30 \mu \mathrm{l} / \mathrm{min}$ for $3 \mathrm{~min}$. The binding response (black line) in resonance units is plotted against time (s). Binding kinetics of the interactions between rKAAs and gp120 (overlaid red line) were calculated by fitting the data to Langmuir model for 1:1 binding. c Comparison of binding activity to gp120 among KAAs including His-rKAA-1, rKAA-1, KAA-1, and KAA-2. SPR analysis was performed using $0.98 \mathrm{nM}$ of each lectin solution by the same method as described above (color figure online) 
Table 3 Summary of binding kinetics of the interactions between rKAAs and gp120

\begin{tabular}{lllll}
\hline Lectin & $\mathrm{k}_{\mathrm{a}}\left(\mathrm{M}^{-1} \mathrm{~s}^{-1}\right)$ & $\mathrm{k}_{\mathrm{d}}\left(\mathrm{s}^{-1}\right)$ & $\mathrm{K}_{\mathrm{A}}\left(\mathrm{M}^{-1}\right)$ & $\mathrm{K}_{\mathrm{D}}(\mathrm{M})$ \\
\hline His-rKAA-1 & $8.71 \times 10^{5}$ & $5.90 \times 10^{-4}$ & $1.48 \times 10^{9}$ & $6.77 \times 10^{-10}$ \\
rKAA-1 & $8.50 \times 10^{5}$ & $5.29 \times 10^{-4}$ & $1.61 \times 10^{9}$ & $6.22 \times 10^{-10}$ \\
\hline
\end{tabular}

$k_{a}$ association rate constant, $k_{d}$ dissociation rate constant, $K_{A}$ association constant, $K_{D}$ dissociation constant

lectin family might have similar carbohydrate-binding specificities.

A detailed oligosaccharide binding analysis by the centrifugal ultrafiltation-HPLC method using PA-sugars revealed that the recombinants, His-rKAA-1 and rKAA-1, preferentially recognized exposed $\alpha 1-3$ Man in the D2 arm of highmannose $N$-glycans (Figs. 8 and 9) as previously reported for native KAA-2 (Sato et al. 2011a). The nonreducing terminal $\alpha 1-2$ linked Man in the D2 arm tended to more negatively affect for binding to rKAAs than native KAA-2. The recognition mode of KAAs is absolutely different from the other high-mannose specific antiviral lectins including CV-N, GRFT, SVN, MVL, and AH (Koharudin and Gronenborn 2014). We also reported the same oligosaccharide binding properties in ESA-2 (Hori et al. 2007) and OAA (Sato et al. 2007), and recently in KSA from K. striatum (Hung et al. 2011) and EDA from E. denticulatum (Hung et al. 2015). A lectin PFL from Pseudomonas fluorescens Pf0-1 belonging to this lectin family also tends to preferentially recognize highmannose glycans with $\alpha 1-3$ Man exposed in the D2 arm but not to other sugar types including complex $\mathrm{N}$-glycans and $O$ glycans, as revealed by screening with a glycan array having 611 glycan targets (Sato et al. 2012). Three-dimentional structure analyses for glycan-bound OAA (Koharudin et al. 2011; Koharudin and Gronenborn 2011), PFA (identical to PFL), MBHA (Koharudin et al. 2012) and BOA (Whitley et al. 2013) supported their strict binding specificities; the amino acid residues which were revealed to interact with branched mannoside in the high-mannose glycans by tertiary-structural analyses were absolutely conserved in all the lectins of this family as mentioned above (Fig. 6). In previous (Sato et al. 2011a) and present studies, native KAA-2 and rKAAs bound to high-mannose-type oligosaccharides but not or little to oligomannoses including PA-mannopentaose (Man $\alpha 1$ 6(Man $\alpha 1-3)$ Man $\alpha 1-6($ Man $\alpha 1-3) M a n-P A)$ (oligosaccharide 22 in Fig. 8), suggesting a possibility that the reducing

Table 4 Neutralization of HIV-1 by native KAAs and a recombinant KAA-1

\begin{tabular}{lc}
\hline Lectin & $\mathrm{IC}_{50}(\mathrm{nM})( \pm \mathrm{SD})$ \\
\hline KAA-1 & $9.2 \pm 2.2$ \\
KAA-2 & $7.3 \pm 1.9$ \\
His-rKAA-1 & $12.9 \pm 2.2$ \\
\hline
\end{tabular}

$S D$ standard deviation terminal disaccharide GlcNAc-GlcNAc is necessary for KAAs to bind to high-mannose $N$-glycans. On the other hand, Koharudin and Gronenborn (2011) showed that OAA binds to this type of mannopentaose (not pyridylaminated), by NMR binding studies, and suggested that the reducing terminal disaccharide was not essential for OAA to bind to those glycans. Exactly, PA-oligosaccharides used in this study possessed the reducing terminal residues with ring-opening structures by pyridylamination, including free oligomannoses (PA-oligosaccharides $18-22$ in Fig. 8). Thus, it might be attributable to such ring-opening of the reducing terminal residues that KAAs did not bind to the PA-oligomannoses, including mannopentaose (Man $\alpha 1-6(\operatorname{Man} \alpha 1-3) \operatorname{Man} \alpha 1-6(\operatorname{Man} \alpha 1-$ 3)Man-PA) (oligosaccharide 22 in Figs. 8 and 9). Although we have not elucidated the structure of a KAAmannopentaose complex, it is strongly predicted that KAA, as well as OAA (Koharudin et al. 2011), requires the reducing terminal mannose having the ring structure for binding to mannopentaose, unlike that CV-N and GRFT do not directly interact with the reducing terminal mannose (Ziolkowska et al. 2006; Ziolkowska and Wlodawer 2006).

SPR analyses revealed that rKAAs bound to HIV envelope glycoprotein gp120 with high association constants (1.48$1.61 \times 10^{9} \mathrm{M}^{-1}$ ) as well as native KAAs did (Fig. 10). gp120 is extensively glycosylated with $N$-linked complex and high-mannose carbohydrates accounting for about half of its molecular weight (Geyer et al. 1988), suggesting that KAAs can bind gp120 with a high affinity for the highmannose sugars. Supposed from their strong binding to the gp120, KAAs represented potent anti-HIV activities at $\mathrm{IC}_{50}$ of nanomolar levels (7.3-12.9 nM, Table 4) in virus neutralization assay with Jurkat cells. The activities were comparable to those of OAA (12 nM of $\mathrm{IC}_{50}$ against HIV-1 (R9) in TZM-b1 cells (Koharudin et al. 2012), $45 \mathrm{nM}$ of $\mathrm{EC}_{50}$ against HIV-1 X4 in MT-4 cells (Sato et al. 2007)), MBHA (15 $\mathrm{nM}$ of $\mathrm{IC}_{50}$ against HIV-1 (R9) in TZM-b1 cells (Koharudin et al. 2012)), BOA (12.2 nM of IC $_{50}$ against HIV-1 (R9) in TZM-b1 cells (Whitley et al. 2013)) and ESA-2 (165 $\mathrm{nM}$ of $\mathrm{EC}_{50}$ against HIV-1 X4 in MT-4 cells (Sato et al. 2007)). There are a lot of HIV-1 strains, being suggested that there may be distinct sugar structures on their envelope gp120 (Zhang et al. 2004). The difference of anti-HIV activities, such as the activities of OAA against HIV-1 (R9) in TZM-b1 and HIV-1 X4 in MT-4 cells, may be caused by the difference of virus strains and cells (Huskens and Schols 2012) used in the experiments. The anti-HIV activities of CV-N and GRFT were reported as $0.4 \mathrm{nM}$ (against HIV-1 (R9) in TZM-b1 cells) and $0.04 \mathrm{nM}$ (against HIV-1 X4 in MT-4 cells) of $\mathrm{IC}_{50}$ (or $\mathrm{EC}_{50}$ ), respectively (Koharudin et al. 2012; Mori et al. 2005). The interaction between GRFT and HIV-1 gp120 IIIB (X4) was also elucidated by Xue et al. (2013) via a SPR analysis using a BIAcore T200; the dissociation constant of GRFT with the gp120 is $6.93 \times 10^{-11} \mathrm{M}$, which is 10 -fold lower than those 
of KAAs $\left(6.22-6.77 \times 10^{-10} \mathrm{M}\right)$ (Fig. 10). These relatively strong anti-HIV-1 activities of CV-N and GRFT and the robust interaction of GRFT with gp120 come from the multivalency of binding sites on the lectins and that of epitopes on the highmannose oligosaccharides (Koharudin and Gronenborn 2014). Although the anti-viral activities of KAAs are lower than those of CV-N and GRFT, the oligomannose epitopes recognized by KAAs are different from those recognized by CV-N and GRFT. Since high mutation rate in HIV-1 can rapidly produce the resistant viruses against these anti-viral lectins (Witvrouw et al. 2005; Huang et al. 2011), multilateral and synergistic use of the anti-viral lectins whose recognition epitopes in oligosaccharides are different from one another can be effective as Férir et al. (2014) represented.

We searched higher plant lectins similar to KAAs by in silico screening for genome sequences of soybean Glycine max, rice Oryza sativa, and Arabidopsis; however, higher plant genomes encode no lectins similar to this lectin family (data not shown) as Jiang et al. (2010) reported a genome wide screening of higher plant lectins. This lectin family is found to date only in lower organisms including eukaryotes of red algae and prokaryotes of cyanobacteria and bacteria. The biofunctional mechanism(s) where this lectin family preferentially binds to high-mannose carbohydrates having an exposed

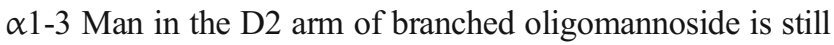
uncovered. As Yoshiie et al. (2012) reported that the $N$-glycans of glycoproteins in red algae are predominantly highmannose types, the internal ligands of KAAs could exist in the cells, implied from the predicted nucleocytoplasmic localization of the lectins as described before. However, the lectins peculiar to these lower organisms may have common function(s), such as host defense against infections of invasive viruses, bacteria, or fungi to these organisms as well as several cytoplasmic/nuclear plant lectins, including amaranthins, Euonymus lectin-like (EUL)-related lectins, jacalin-related lectins, and nictaba-related lectins, have an important role in plant defense against pathogens (Lannoo and Van Damme 2010, 2014; Dias Rde et al. 2015; De Schutter and Van Damme 2015).

This study showed that the lectins from the cultivated alga $K$. alvarezii inhibit the HIV virus entry to the host cells through binding to the virus envelope glycoprotein gp120 and confirmed their activities using its recombinants. These results suggested that KAAs have potentiality to represent broad anti-viral activities against viruses possessing highmannose glycans on their envelope such as HCV, HHV, SARS-CoV, and Ebola virus, as well as native KAA-2 did against influenza viruses (Sato et al. 2011a). It is important that anti-viral lectins are isolated from a globally cultivated edible algal species in contrast that any other homologous anti-HIV lectins are derived from bacteria (BOA, PFL, MBHA), a cyanobacterium (OAA), and an uncultivated alga (ESA-2); KAAs can be purified in a relatively high yield of
$270 \mathrm{mg}$ per $100 \mathrm{~g}$ of freeze-dried alga (Kawakubo et al. 1999). These functional lectins will become a strong tool by being supplied in bulk as both native and recombinant forms, which are almost identical in their carbohydrate specificities and anti-viral activities.

Acknowledgments Jurkat cells and pNL4-3 were kindly provided by Dr. Tsutomu Murakami in AIDS Research Center, National Institute of Infectious Diseases, Japan. We thank Dr. Tomoko Amimoto in the Natural Science Center for Basic Research and Development (N-BARD) at Hiroshima University for measuring the ESI-MS data. This work was partially supported by the Program for Promotion of Basic and Applied Researches for Innovations in Bio-Oriented Industry of Japan.

\section{Compliance with Ethical Standards}

Conflict of Interest No conflicts of interest are declared.

\section{References}

Adachi A, Gendelman HE, Koenig S, Folks T, Willey R, Rabson A, Martin MA (1986) Production of acquired immunodeficiency syndrome-associated retrovirus in human and nonhuman cells transfected with an infectious molecular clone. J Virol 59:284-291

Ask EI, Batibasaga A, Zertuche-Gonzalez JA, de San M (2003) Three decades of Kappaphycus alvarezii (Rhodophyta) introduction to non-endemic locations. In: Chapman ARO, Anderson RJ, Vreeland VJ, Davison IR (eds) Proceedings of the 17th international seaweed symposium, Cape Town, South Africa, pp 49-57

Balzarini J, Schols D, Neyts J, Van Damme E, Peumans W, De Clercq E (1991) Alpha-(1-3)- and alpha-(1-6)-D-mannose-specific plant lectins are markedly inhibitory to human immunodeficiency virus and cytomegalovirus infections in vitro. Antimicrob Agents Chemother 35:410-416

Barrientos LG, O'Keefe BR, Bray M, Sanchez A, Gronenborn AM, Boyd MR (2003) Cyanovirin-N binds to the viral surface glycoprotein, GP1,2 and inhibits infectivity of Ebola virus. Antiviral Res 58:4756

Bewley CA, Cai M, Ray S, Ghirlando R, Yamaguchi M, Muramoto K (2004) New carbohydrate specificity and HIV-1 fusion blocking activity of the cyanobacterial protein MVL: NMR, ITC and sedimentation equilibrium studies. J Mol Biol 339:901-914

Bindu MS, Levine IA (2011) The commercial red seaweed Kappaphycus alvarezii-an overview on farming and environment. J Appl Phycol 23:789-796

Bokesch HR, O'Keefe BR, McKee TC, Pannell LK, Patterson GM, Gardella RS, Sowder RC 2nd, Turpin J, Watson K, Buckheit RW Jr, Boyd MR (2003) A potent novel anti-HIV protein from the cultured cyanobacterium Scytonema varium. Biochemistry 42:25782584

Bonomelli C, Doores KJ, Dunlop DC, Thaney V, Dwek RA, Burton DR, Crispin M, Scanlan CN (2011) The glycan shield of HIV is predominantly oligomannose independently of production system or viral clade. PLoS One 6:e23521

Boyd MR, Gustafson KR, McMahon JB, Shoemaker RH, O'Keefe BR, Mori T, Gulakowski RJ, Wu L, Rivera MI, Laurencot CM, Currens MJ, Cardellina JH 2nd, Buckheit RW Jr, Nara PL, Pannell LK, Sowder RC 2nd, Henderson LE (1997) Discovery of cyanovirin$\mathrm{N}$, a novel human immunodeficiency virus-inactivating protein that binds viral surface envelope glycoprotein gp120: potential 
applications to microbicide development. Antimicrob Agents Chemother 41:1521-1530

Charan RD, Munro MH, O'Keefe BR, Sowder RCII, McKee TC, Currens MJ, Pannell LK, Boyd MR (2000) Isolation and characterization of Myrianthus holstii lectin, a potent HIV-1 inhibitory protein from the plant Myrianthus holstii. J Nat Prod 63:1170-1174

Chen J, Song JI, Zhang S, Wang Y (1999) Chaperon activity of DsbC. J Biol Chem 274:19601-19605

Chiba H, Inokoshi J, Okamoto M, Asanuma S, Matsuzaki K, Iwama M, Mizumoto K, Tanaka H, Oheda M, Fujita K, Nakashima H, Shinose M, Takahashi Y, Omura S (2001) Actinohivin, a novel anti-HIV protein from an actinomycete that inhibits syncytium formation: isolation, characterization, and biological activities. Biochem Biophys Res Commun 282:595-601

Cumsky M, Zusman DR (1979) Myxobacterial hemagglutinin: a development-specific lectin of Myxococcus xanthus. Proc Natl Acad Sci U S A 76:5505-5509

De Schutter K, Van Damme EJM (2015) Protein-carbohydrate interactions as part of plant defense and animal immunity. Molecules 20: 9029-9053

Dey B, Lerner DL, Lusso P, Boyd MR, Elder JH, Berger EA (2000) Multiple antiviral activities of cyanovirin-N: blocking of human immunodeficiency virus type 1 gp120 interaction with CD4 and coreceptor and inhibition of diverse enveloped viruses. J Virol 74: $4562-4569$

Dias Rde O, Machado Ldos S, Migliolo L, Franco OL (2015) Insights into animal and plant lectins with antimicrobial activities. Molecules 20:519-541

Doty MS (1973) Farming the red seaweed, Eucheuma, for carrageenans. Micronesia 9:59-73

Férir G, Huskens D, Noppen S, Koharudin LM, Gronenborn AM, Schols D (2014) Broad anti-HIV activity of the Oscillatoria agardhii agglutinin homologue lectin family. J Antimicrob Chemother 69: 2746-2758

Fouquaert E, Hanton SL, Brandizzi F, Peumans WJ, Van Damme EJ (2007) Localization and topogenesis studies of cytoplasmic and vacuolar homologs of the Galanthus nivalis agglutinin. Plant Cell Physiol 48:1010-1021

Geyer H, Holschbach C, Hunsmann G, Schneider J (1988) Carbohydrates of human immunodeficiency virus. Structures of oligosaccharides linked to the envelope glycoprotein 120. J Biol Chem 263:11760 11767

Gill SC, von Hippel PH (1989) Calculation of protein extinction coefficients from amino acid sequence data. Anal Biochem 182:319-326

Hansen JE, Nielsen CM, Nielsen C, Heegaard P, Mathiesen LR, Nielsen JO (1989) Correlation between carbohydrate structures on the envelope glycoprotein gp120 of HIV-1 and HIV-2 and syncytium inhibition with lectins. AIDS 3:635-641

Helle F, Wychowski C, Vu-Dac N, Gustafson KR, Voisset C, Dubuisson J (2006) Cyanovirin- $\mathrm{N}$ inhibits hepatitis $\mathrm{C}$ virus entry by binding to envelope protein glycans. J Biol Chem 281:25177-25183

Hori K, Hirayama M (2014) Centrifugal ultrafiltration-HPLC method for interaction analysis between lectins and sugars. In: Hirabayashi J (ed) Lectins. Springer New York, NY, pp 173-183

Hori K, Miyazawa K, Ito K (1986) Preliminary characterization of agglutinins from seven marine algal species. Bull Jpn Soc Sci Fish 52: 323-331

Hori K, Sato Y, Ito K, Fujiwara Y, Iwamoto Y, Makino H, Kawakubo A (2007) Strict specificity for high-mannose type $N$-glycans and primary structure of a red alga Eucheuma serra lectin. Glycobiology 17:479-491

Huang X, Jin W, Griffin GE, Shattock RJ, Hu Q (2011) Removal of two high-mannose $\mathrm{N}$-linked glycans on gp120 renders human immunodeficiency virus 1 largely resistant to the carbohydrate-binding agent griffithsin. J Gen Virol 92:2367-2373
Hung LD, Sato Y, Hori K (2011) High-mannose N-glycan-specific lectin from the red alga Kappaphycus striatum (carrageenophyte). Phytochemistry 72:855-861

Hung LD, Hirayama M, Ly BM, Hori K (2015) Purification, primary structure, and biological activity of the high-mannose $\mathrm{N}$-glycan-specific lectin from cultivated Eucheuma denticulatum. J Appl Phycol 27:1657-1669

Huskens D, Schols D (2012) Algal lectins as potential HIV microbicide candidates. Mar Drugs 10:1476-1497

Imai K, Nakai K (2010) Prediction of subcellular locations of proteins: where to proceed? Proteomics 10:3970-3983

Jiang SY, Ma Z, Ramachandran S (2010) Evolutionary history and stress regulation of the lectin superfamily in higher plants. BMC Evol Biol 10:79

Kawakubo A, Makino H, Ohnishi J, Hirohara H, Hori K (1997) The marine red alga Eucheuma serra J. Agardh, a high yielding source of two isolectins. J Appl Phycol 9:331-338

Kawakubo A, Makino H, Ohnishi J, Hirohara H, Hori K (1999) Occurrence of highly yielded lectins homologous within the genus Eucheuma. J Appl Phycol 11:149-156

Kilby JM, Eron JJ (2003) Novel therapies based on mechanisms of HIV-1 cell entry. N Engl J Med 348:2228-2238

Koharudin LMI, Gronenborn AM (2011) Structural basis of the anti-HIV activity of the cyanobacterial Oscillatoria agardhii agglutinin. Structure 19:1170-1181

Koharudin LMI, Gronenborn AM (2014) Antiviral lectins as potential HIV microbicides. Curr Opin Virol 7:95-100

Koharudin LMI, Furey W, Gronenborn AM (2011) Novel fold and carbohydrate specificity of the potent anti-HIV cyanobacterial lectin from Oscillatoria agardhii. J Biol Chem 286:1588-1597

Koharudin LMI, Kollipara S, Aiken C, Gronenborn AM (2012) Structural insights into the anti-HIV activity of the Oscillatoria agardhii agglutinin homolog lectin family. J Biol Chem 287: 33796-33811

Lannoo N, Van Damme EJM (2010) Nucleocytoplasmic plant lectins. Biochim Biophys Acta 1800:190-201

Lannoo N, Van Damme EJM (2014) Lectin domains at the frontiers of plant defense. Front Plant Sci 5:397

Mori T, O'Keefe BR, Sowder RC 2nd, Bringans S, Gardella R, Berg S, Cochran P, Turpin JA, Buckheit RW Jr, McMahon JB, Boyd MR (2005) Isolation and characterization of griffithsin, a novel HIVinactivating protein, from the red alga Griffithsia sp. J Biol Chem 280:9345-9353

Nelson DR, Cumsky MG, Zusman DR (1981) Localization of myxobacterial hemagglutinin in the periplasmic space and on the cell surface of Myxococcus xanthus during developmental aggregation. J Biol Chem 256:12589-12595

O'Keefe BR, Smee DF, Turpin JA, Saucedo CJ, Gustafson KR, Mori T, Blakeslee D, Buckheit R, Boyd MR (2003) Potent anti-influenza activity of cyanovirin-N and interactions with viral hemagglutinin. Antimicrob Agents Chemother 47:2518-2525

O'Keefe BR, Giomarelli B, Barnard DL, Shenoy SR, Chan PK, McMahon JB, Palmer KE, Barnett BW, Meyerholz DK, Wohlford-Lenane CL, McCray PB Jr (2010) Broad-spectrum in vitro activity and in vivo efficacy of the antiviral protein griffithsin against emerging viruses of the family Coronaviridae. J Virol 84: 2511-2521

Okuno T, Shao H, Asada H, Shiraki K, Takahashi M, Yamanishi K (1992) Analysis of human herpesvirus 6 glycoproteins recognized by monoclonal antibody OHV1. J Gen Virol 73:443-447

Pace CN, Vajdos F, Fee L, Grimsley G, Gray T (1995) How to measure and predict the molar absorption coefficient of a protein. Protein Sci 4:2411-2423

Parker HS (1974) The culture of the red algal genus Eucheuma in the Philippines. Aquaculture 3:425-439 
Sato T, Hori K (2009) Cloning, expression, and characterization of a novel anti-HIV lectin from the cultured cyanobacterium, Oschillatoria agardhii. Fish Sci 75:743-753

Sato Y, Murakami M, Miyazawa K, Hori K (2000) Purification and characterization of a novel lectin from a freshwater cyanobacterium, Oscillatoria agardhii. Comp Biochem Physiol B 125:169-177

Sato Y, Okuyama S, Hori K (2007) Primary structure and carbohydrate binding specificity of a potent anti-HIV lectin isolated from the filamentous cyanobacterium Oscillatoria agardhii. J Biol Chem 282:11021-11029

Sato Y, Morimoto K, Hirayama M, Hori K (2011a) High-mannosespecific lectin (KAA-2) from the red alga Kappaphycus alvarezii potently inhibits influenza virus infection in a strain-independent manner. Biochem Biophys Res Commun 405:291-296

Sato Y, Hirayama M, Morimoto K, Yamamoto N, Okuyama S, Hori K (2011b) High-mannose-binding lectin with preference for the cluster of $\alpha 1-2$-mannose from the green alga Boodlea coacta is a potent entry inhibitor of HIV-1 and influenza viuses. J Biol Chem 286: 19446-19458

Sato Y, Morimoto K, Kubo T, Yanagihara K, Seyama T (2012) Highmannose-binding antiviral lectin PFL from Pseudomonas fluorescens $\mathrm{Pf0}-1$ promotes cell death of gastric cancer cell MKN28 via interaction with $\alpha 2$-integrin. PLoS One 7:e45922

Schägger H, von Jagow G (1987) Tricine-sodium dodecyl sulfatepolyacrylamide gel electrophoresis for the separation of proteins in the range from 1 to $100 \mathrm{kDa}$. Anal Biochem 166:368-379

Sievers F, Wilm A, Dineen D, Gibson TJ, Karplus K, Li W, Lopez R, McWilliam H, Remmert M, Söding J, Thompson JD, Higgins DG (2011) Fast, scalable generation of high-quality protein multiple sequence alignments using Clustal Omega. Mol Syst Biol 7:539

Swanson MD, Winter HC, Goldstein IJ, Markovitz DM (2010) A lectin isolated from bananas is a potent inhibitor of HIV replication. J Biol Chem 285:8646-8655

Van Hove J, Fouquaert E, Smith DF, Proost P, Van Damme EJM (2011) Lectin activity of the nucleocytoplasmic EUL protein from Arabidopsis thaliana. Biochem Biophys Res Commun 414:101-105
Vigerust DJ, Shepherd VL (2007) Virus glycosylation: role in virulence and immune interactions. Trends Microbiol 15:211-218

Wei X, Decker JM, Wang S, Hui H, Kappes JC, Wu X, Salazar-Gonzalez JF, Salazar MG, Kilby JM, Saag MS, Komarova NL, Nowak MA, Hahn BH, Kwong PD, Shaw GM (2003) Antibody neutralization and escape by HIV-1. Nature 422:307-312

Whitley MJ, Furey W, Kollipara S, Gronenborn AM (2013) Burkholderia oklahomensis agglutinin is a canonical two-domain OAA-family lectin: structures, carbohydrate binding and anti-HIV activity. FEBS J 280:2056-2067

Witvrouw M, Fikkert V, Hantson A, Pannecouque C, O'Keefe BR, McMahon J, Stamatatos L, de Clercq E, Bolmstedt A (2005) Resistance of human immunodeficiency virus type 1 to the highmannose binding agents cyanovirin $\mathrm{N}$ and concanavalin A. J Virol 79:7777-7784

Xue J, Hoorelbeke B, Kagiampakis I, Demeler B, Balzarini J, LiWang PJ (2013) The Griffithsin dimer is required for high-potency inhibition of HIV-1: evidence for manipulation of the structure of gp120 as part of the griffithsin dimer mechanism. Antimicrob Agents Chemother 57:3976-3989

Yoshiie T, Maeda M, Kimura M, Hama Y, Uchida M, Kimura Y (2012) Structural features of $\mathrm{N}$-glycans of seaweed glycoproteins: Predominant occurrence of high-mannose type $\mathrm{N}$-glycans in marine plants. Biosci Biotechnol Biochem 76:1996-1998

Zhang M, Gaschen B, Blay W, Foley B, Haigwood N, Kuiken C, Korber B (2004) Tracking global patterns of N-linked glycosylation site variation in highly variable viral glycoproteins: HIV, SIV, and $\mathrm{HCV}$ envelopes and influenza hemagglutinin. Glycobiology 14: 1229-1246

Ziolkowska NE, Wlodawer A (2006) Structural studies of algal lectins with anti-HIV activity. Acta Biochim Pol 53:617-626

Ziolkowska NE, O'Keefe BR, Mori T, Zhu C, Giomarelli B, Vojdani F, Palmer KE, McMhon JB, Wlodawer A (2006) Domain-swapped structure of the potent antiviral protein griffithsin and its mode of carbohydrate binding. Structure 7:1127-1135 